\title{
Top-down, Bottom-up or In-between: How Can a UNFCCC Framework for Market-Based Approaches Ensure Environmental Integrity and Market Coherence?
}

\section{Joëlle de Sépibus,* Wolfgang Sterk,** Andreas Tuerk***}

\begin{abstract}
The Durban Climate Conference agreed on the creation of a new market-based mechanism under the United Nations Framework Convention on Climate Change (UNFCCC) and to consider the establishment of an overall framework for various mitigation approaches, including opportunities for using markets ("Framework"). This development is taking place against the background of increasing numbers of parties developing market mechanisms outside the UNFCCC. The creation of such a Framework is therefore of high political significance, as it should ensure on the one hand that new market-based mechanisms contribute to global climate change mitigation and to achievement of targets and on the other hand that different market-based approaches can be integrated in a global carbon market. As yet there is little clarity as to the roles and design of such a framework. This paper contributes to the debate by discussing and evaluating inter alia several design options, and explores how the various options could be implemented and how they interrelate. The paper concludes that a strong central oversight at the level of the UNFCCC is probably the only option that could reassure the vast majority of UNFCCC Parties that the environmental integrity of new market-based mechanisms is in fact ensured. This does, however, not exclude that some reasonable balance may be struck between centralisation and flexibility.
\end{abstract}

Key words: market-based mechanisms, climate change, carbon markets, mitigation, UNFCCC, negotiations, post-2012 climate regime

\section{FNDSNF}


Research for this paper was funded by the Swiss National Science Foundation under a grant to the National Centre of Competence in Research on Trade Regulation, based at the World Trade Institute of the University of Bern, Switzerland.

\section{Contents}

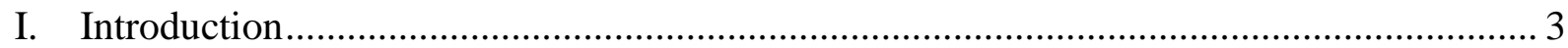

II. New Market Mechanisms in the post-2012 context ........................................................ 5

2.1 The clarification process of post-2012 mitigation targets of developed countries........... 5

2.2 Developed countries' intended future use of carbon markets ....................................... 7

III. Countries' positions on the NMM and the Framework ........................................... 13

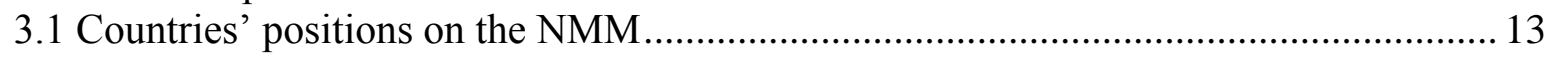

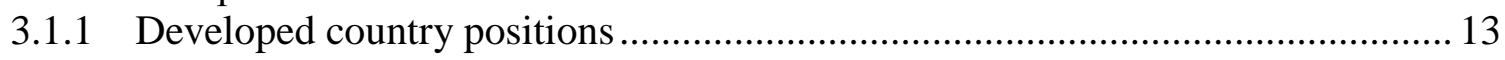

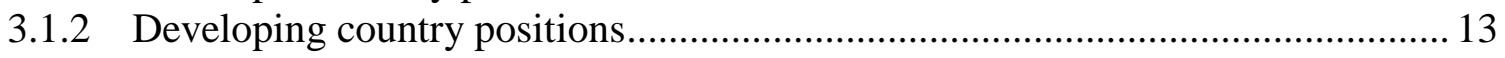

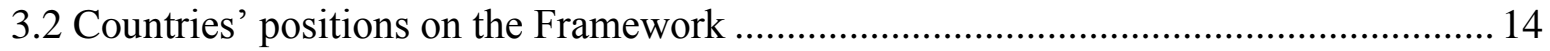

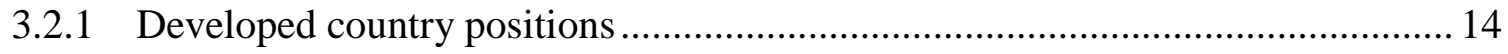

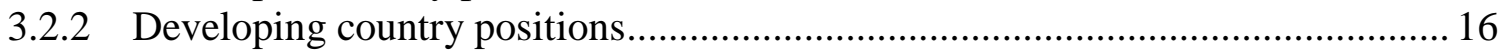

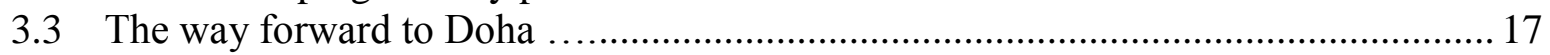

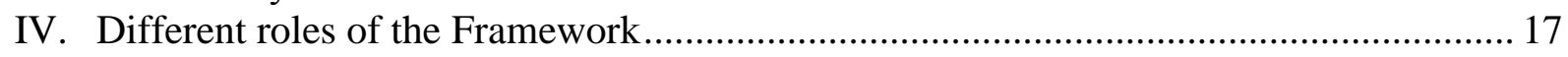

4.1 Assisting developed countries in achieving their emission targets ........................... 18

4.2 Ensuring environmental integrity as well as achieving net emission reductions ......... 18

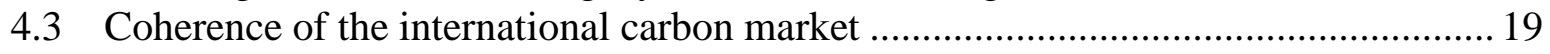

V. Design options under the Framework ....................................................................... 19

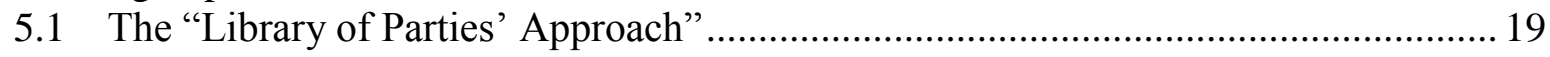

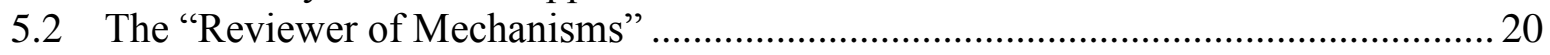

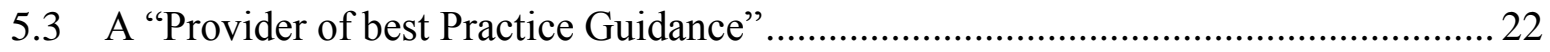

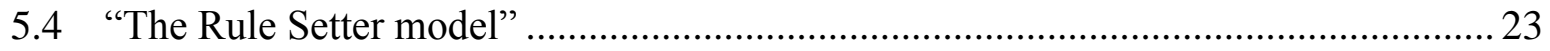

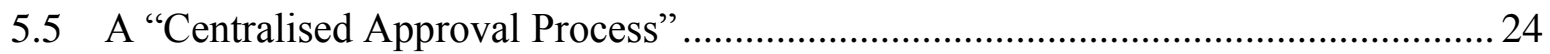

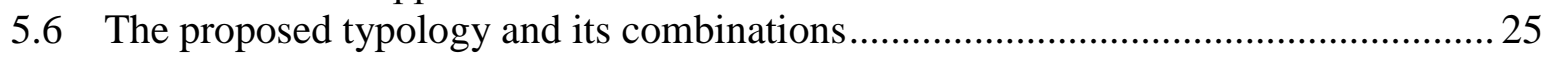

VI. Evaluation of the various designs with the Durban mandate ....................................... 26

6.1 Standards that deliver real, permanent, additional and verified mitigation outcomes and achieve a net decrease and/or avoidance of greenhouse gas emissions .......................26

6.2 Standards that avoid double-counting of efforts ................................................... 28

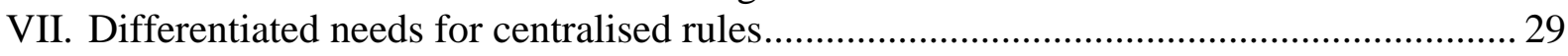

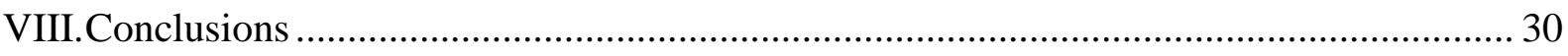

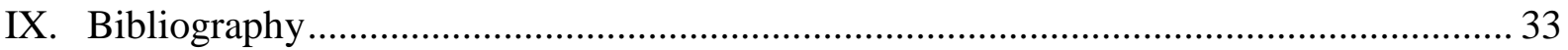




\section{Introduction}

In December 2011, at the annual Conference of the Parties (COP) to the United Nations Framework Convention on Climate Change (UNFCCC) in Durban (COP17), Parties agreed to start negotiations with the aim of crafting a new legally binding global climate treaty, or an outcome with "legal force" by the end of 2015 with entry into force by $2020 .{ }^{1}$ Moreover, the Parties decided to extend the Kyoto Protocol (KP) by adopting a second commitment period, thereby securing the continuation of the Clean Development Mechanism ${ }^{2}$ (CDM) as well as most of the rules established by the Marrakesh Accords, in particular the greenhouse gas (GHG) accounting rules. ${ }^{3}$ The significance of this decision, touted as one of the COP17's most important achievements is, however, reduced by the turning away of Japan, Russia and Canada from a further Kyoto commitment period, and the possible refusal of New Zealand and Australia to remain bound by the KP rules. Also, the individual emissions caps of the various Kyoto Parties still have to be translated into quantified emission limitation and reduction obligations (QUELROs) at COP18 in Doha at the end of 2012.

In addition, the Durban conference took decisions on the creation of new market-based mechanisms, a topic which had already been under discussion for several years, but with little progress. ${ }^{4}$ These debates have in particular been promoted by industrialised countries, which have taken the position that an important part of the financial support needed by developing countries could and should be delivered through the carbon market. In addition, most industrialised countries have tied their emission reduction pledges to access to a functioning carbon market. The EU even put forward the creation of a new market mechanism as one of its preconditions for accepting a second Kyoto commitment period.

The main idea of new market mechanisms is that markets should promote climate-friendly policies and not only isolated projects. Further, many industrialised countries are dissatisfied with the existing CDM. Due to its design as a project-based mechanism, the CDM does not encourage structural changes that support a broad transition towards low-carbon economies in developing countries. ${ }^{5}$

COP17 fulfilled the mandate formulated by the Cancun Agreements to elaborate one or more market mechanisms. ${ }^{6}$ It took the decision to pursue two tracks. First, it decided to establish a "new market-based mechanism" (NMM) that should be operated "under the guidance and authority of the COP" ${ }^{\prime 7}$. Second, it resolved to consider the establishment of a framework for

\footnotetext{
${ }^{1}$ Parties agreed to launch a process "to develop a protocol, another legal instrument or an agreed outcome with legal force under the Convention applicable to all Parties”. See Decision 1/CP.17 on the Establishment of an Ad Hoc Working Group on the Durban Platform for Enhanced Action.

${ }^{2}$ See Art. $12 \mathrm{KP}$.

${ }^{3}$ Under the KP, developed countries account for their emissions and emission reductions in accordance with a set of common rules that apply inter alia to the coverage of sectors and gases, the use of common metrics, land use, land-use change and forestry (LULUCF) accounting, mechanisms and carry-over of units to the next commitment period. They are required to translate limitation or reduction commitments into absolute quantified emissions units to ensure accurate tracking of emissions levels and demonstrate compliance. See de Sépibus et al. (2011: 10)

${ }^{4}$ Marcu (2011b).

${ }^{5}$ See Sterk (2010: 3).

${ }^{6} 1 / \mathrm{CP} .16$, para $80 \mathrm{ff}$.

${ }^{7}$ 2/CP.17, para $83 \mathrm{ff}$.
} 
"various approaches, including opportunities for using markets" ("Framework"). ${ }^{8}$ The NMM "may assist developed countries to meet part of their mitigation targets or commitments under the Convention" and should be guided by the respective decision made in Cancun. ${ }^{9}$ In addition, an NMM has to stimulate the reduction of GHG emissions across "broad segments of the economy" and generate units for efforts that go beyond pure offsetting in developing countries. The aim of the Framework is, in comparison, less clear. The text merely mentions that it "must meet standards that deliver real, permanent, additional and verified emissions reductions, avoid double counting of efforts, and achieve a net decrease and/or avoidance of greenhouse gas emissions". 10

For both the $\mathrm{NMM}^{11}$ and the Framework ${ }^{12}$ the Ad Hoc Working Group on Long-term Cooperative Action (AWG-LCA) is requested to conduct a work programme during 2012, with the aim to "elaborate modalities and procedures" for the former and "with a view to recommending a decision" for the latter. Furthermore, Parties and accredited observer organizations were invited to submit their views by March 2012, sharing in particular the lessons learned through their experiences with existing mechanisms (see section 3 for the content of the submissions of the Parties). ${ }^{13}$

The reason for opting for a dual approach with respect to the creation of new market-based mechanisms is that a compromise had to be reached to address the diverging views of Parties related to the governance of the future mechanisms and the GHG accounting framework underlying them. ${ }^{14}$ The submissions of Parties in the run-up to Durban had indeed revealed a substantial divide between the views of countries like Japan, New Zealand and Australia on the one hand which expressed a clear preference for decentralised governance allowing for an "efficient, effective and flexible approach" suited to national circumstances and needs, and the European Union (EU) and developing countries on the other hand. The latter favour more centralised governance with common rules and a strong supervisory body ensuring its smooth functioning and guaranteeing the environmental integrity of the mechanism. ${ }^{15}$

This divergence of views, which essentially centres on the question whether new market mechanisms would have to comply with a common set of internationally agreed rules under the oversight of the UNFCCC, ${ }^{16}$ reflects more fundamentally the different perception by Parties of the adequacy of the rules laid down by the Kyoto Protocol and the Marrakesh Accords. While the United States have never adhered to them, the refusal to sign up for a second commitment period by countries such as Canada, Japan and Russia, and possibly Australia and New Zealand, shows the growing discontent of these countries with the current

\footnotetext{
${ }^{8}$ 2/CP.17, para $79 \mathrm{ff}$.

${ }^{9} 1 /$ CP. 16, par. 80 : "Decides to consider the establishment, at the seventeenth session of the Conference of the Parties, of one or more market-based mechanisms to enhance the cost-effectiveness of, and to promote, mitigation actions, taking into account the following: (a) Ensuring voluntary participation of Parties, supported by the promotion of fair and equitable access for all Parties; (b) Complementing other means of support for nationally appropriate mitigation actions by developing country Parties; (c) Stimulating mitigation across broad segments of the economy; (d) Safeguarding environmental integrity; (e) Ensuring a net decrease and/or avoidance of global greenhouse gas emissions; (f) Assisting developed country Parties to meet part of their mitigation targets, while ensuring that the use of such a mechanism or mechanisms is supplemental to domestic mitigation efforts; (g) Ensuring good governance and robust market functioning and regulation.”

${ }^{10} 2 / \mathrm{CP} .17$, par. 79.

${ }^{11} 2 / \mathrm{CP} .17$, par. 84 .

12 2/CP.17, par. 80 .

${ }^{13}$ 2/CP.17, para 81 (Framework) and 85 (NMM).

${ }^{14}$ See Marcu (2011a: 3), Sterk et al. (2011).

${ }^{15}$ See for a detailed description of the views of the Parties in the run up to Durban de Sépibus et al. (2011: $8 \mathrm{ff}$.)

${ }^{16}$ See Marcu (2011a: 3).
} 
rules and principles. Although this scepticism is fed by different motivations and may not in all cases boil down to a straightforward rejection of common GHG accounting rules, these Parties probably share the view that a more fragmented approach, allowing for more flexibility, will promote not only more cost-efficient approaches but also offer room for manoeuvre for experimentation fostering a learning process. ${ }^{17}$

On the other hand, the group of countries, notably the EU and the Alliance of Small Island States (AOSIS), supporting the continuation of the KP and a more centralised oversight for new market-based mechanisms, fear that a fragmented, more "bottom-up" approach for the establishment of internationally recognised units might progressively erode the credibility of the climate change regime. Stressing that both investors and host countries of bilateral market mechanisms have an interest in ensuring the generation of the greatest number of credits possible, their concern is that, in the absence of robust international oversight, the environmental integrity of the credits generated may not be guaranteed and cases of fraud may not be addressed by the international community.

Given the numerous studies currently being undertaken on centralised new market mechanisms, ${ }^{18}$ this study puts the emphasis on the possible roles and design options for the Framework. It is structured as follows. First, it provides an overview of the post-2012 context in which new market mechanisms should be used. Second, it presents the Parties' submissions on NMMs $^{19}$ and the Framework ${ }^{20}$. Third, it explores the various functions of the Framework. Fourth, it presents possible design options and evaluates them in the light of the objectives set by the outcome of the AWG-LCA in Durban. ${ }^{21}$ Finally, it discusses the need for centralisation for each design element. The paper concludes with an outlook on possible compromises that might be reached by COP18.

\section{New Market Mechanisms in the post-2012 context}

The debate on a new market mechanisms' regime takes place in a context of uncertainty both with respect to how the post-2012 pledges of developed countries will be calculated and to what extent they may be achieved through the use of credits resulting from new market mechanisms. In the following sections we therefore shed some light on the clarification process of the developed countries' 2020 reduction targets and their intended use of carbon markets.

\subsection{The clarification process of post-2012 mitigation targets of developed countries}

The current mitigation pledges of developed countries have been officially communicated in the aftermath of the Copenhagen summit and "taken note of" by COP16 and CMP6. ${ }^{22}$ The Cancun Agreements ${ }^{23}$ further urged developed countries to upgrade their targets "to a level

\footnotetext{
${ }^{17}$ See de Sépibus et al. (2011).

${ }^{18}$ See inter alia Butzengeiger-Geyer et al. (2011), Harrison et al. (2011), Butzengeiger-Geyer et al. (2010), Helme et al. (2010), OECD (2010), Aasrud et al. (2009), Schneider and Cames (2009), Schmidt et al. (2008).

${ }^{19}$ UNFCCC (2012b).

${ }^{20}$ UNFCCC (2012a).

${ }^{21}$ See $1 /$ CP. 17 , par. 83 .

${ }^{22}$ CMP stands for the Conference of the Parties serving as the Meeting of the Parties of the Kyoto Protocol.

${ }^{23} 1 / \mathrm{CP} .16$.
} 
consistent with" the latest recommendations of the Intergovernmental Panel on Climate Change (IPCC) and called for workshops to clarify the assumptions underlying them. Indeed, although some important parameters of the system for measuring, reporting, and verifying (MRV) countries' targets had been set in Cancun, the underlying assumptions of the targets in particular with respect to global warming potential values (GWP), coverage of gases and sectors, the role of land use change and forestry (LULUCF) and carbon credits from marketbased mechanisms have remained unclear.

In Durban, Parties attempted to gain greater clarity, but no consensus could be reached with respect to common accounting rules or a process to develop such rules under the UNFCCC. ${ }^{24}$ COP17 thus decided to continue in 2012 the process of clarifying developed country Parties' quantified, economy-wide emission-reduction targets as well as to convene an in-session workshop to explore the assumptions and conditions related to these targets. Finally, the UNFCCC Secretariat (the "Secretariat") was requested to prepare a technical paper exploring the commonalities and differences between the Parties' approaches.

In the resulting technical paper, the Secretariat comes to the conclusion that the assumptions on which the countries base their post-2012 targets diverge substantially. ${ }^{25}$ Of particular significance is the system of accounting rules used to determine the contribution of LULUCF to the targets. While under the KP only a few land-use options relying on activity-based approaches have been available, ${ }^{26}$ several countries, including the US, propose to use a comprehensive land-based accounting approach for achieving their post-2012 targets. ${ }^{27}$ Such an approach would significantly affect the stringency of the targets, in particular if "gross-net" accounting is applied. ${ }^{28}$

The pledges made by developed countries for the second commitment period under the KP have been clarified to a large extent. ${ }^{29}$ Notably, it was possible to reach an agreement on new land-use accounting rules, providing for an extension of relevant activities. ${ }^{30}$ So far, however, no decision has been taken with respect to the carry-over of assigned amount units (AAUs) from the first commitment period, the use of credits from new market mechanisms or on the length of the second commitment period. Also, no clarification has been provided as to whether developed country Parties to the KP will use the accounting rules of the KP to assess the achievements of their targets under the Convention.

\footnotetext{
${ }^{24}$ UNDP (2012: 20).

${ }^{25}$ See for a detailed summary of these differences UNFCCC (2012c: 29).

${ }^{26}$ Under the KP, the accounting rules used activity-based approaches. See FCCC/TP/2012/2, p. 20.

${ }^{27}$ A detailed table provided by the EU shows the impact of conditionalities of targets and accounting rules with respect to the pledges. See slide 3 of the presentation of the EU on the clarification of pledges on $18^{\text {th }}$ May 2012 in Bonn. Available on the internet at http://unfccc.int/files/bodies/awglca/application/pdf/20120518_eu_1000.pdf.

${ }^{28}$ The US proposes to use a net-net accounting approach, as opposed to the gross-net approach used under the Kyoto Protocol. Whereas net-net accounting compares the carbon emissions of the commitment period with the base year, gross-net accounting does not. Countries with a growing carbon stock compared to the base year could significantly benefit from a change in accounting rules. Different LULUCF accounting rules could have an impact on global emissions by 2020 of the order of magnitude of several Gt $\mathrm{CO}_{2}$. See European Union (2012). Workshop on the clarification of developed country Parties quantified economy-wide emission reduction targets and related assumptions and conditions of the AWG-LCA 15) on 17 June 2012 in Bonn. Available on the Internet at http://unfccc.int/meetings/bonn_may_2012/workshop/6659.php

${ }^{29}$ See FCCC/KP/AWG/2010/INF.2/Rev.1.

${ }^{30}$ Parties will continue with activity-based approaches to LULUCF in the second commitment period. A major change, however, constitutes the extension to forest management as a mandatory activity included in the accounting rules.
} 
Parallel to this process of the clarification of targets, an improved framework for the reporting of inventories was agreed upon under the Convention, which obliges developed countries to prepare biennial reports on their emissions and on their projects to reduce emissions according to guidelines equally adopted in Durban. ${ }^{31}$ Finally, the modalities for review of these reports, through international assessment and review (IAR) were agreed upon. ${ }^{32}$ Overall, the revised guidelines will provide, from 2015 onwards at the latest, a basis for Parties to use the same coverage of gases, GWP values and methodologies for reporting on their GHG inventories. Yet, this decision does not imply that Parties will apply these rules for calculating their targets.

\subsection{Developed countries' intended future use of carbon markets}

As set out above, there is not yet enough clarity with respect to the use of carbon credits from market-based mechanisms either in terms of their source or of their contribution to the fulfilment of the pledges made by developed countries or countries in transition. ${ }^{33}$ The following section provides some background information on the key players' intentions to seek recourse to market mechanisms. Only developed countries' potential demand for international credits will be discussed. However, Emissions Trading Schemes (ETS) are also being developed in emerging economies, such as in South Korea and Taiwan and may create a demand for international carbon credits. The South Korean scheme, for example, covering about 390 million tonnes of greenhouse gas emissions, will start in 2015, and notably will allow the use of international credits. The amount and types of credits that may be used have not yet been decided.

\section{The European Union}

Creating a global carbon market has long been a key goal of European climate policy. A submission from 2008 had affirmed that the "EU wants to work with other Parties to build a liquid global carbon market with a broad coverage and deep emission cuts to create a robust carbon price signal as a key means to deliver cost-effective GHG emission reductions." "34 Similarly, in its 2009 communication "Towards a comprehensive climate change agreement in Copenhagen", the European Commission maintained that a "global carbon market can and should be built by linking comparable domestic emissions trading systems" and that "the EU should reach out to other countries to ensure an OECD-wide market by 2015 and an even broader market by 2020". As one building block, the Commission proposed to phase out the project-based CDM in advanced developing countries, to be replaced by sectoral carbon crediting mechanisms. These would ultimately "pave the way for the development of cap and trade systems". 35

Correspondingly, the EU is one of the major donors behind the World Bank's Partnership for Market Readiness (PMR). Under the PMR, developing countries are able to receive financial support for capacity building and for piloting market-based climate policy instruments. ${ }^{36}$

\footnotetext{
${ }^{31}$ See decision 15/CP. 17.

${ }^{32}$ The IAR process will be conducted through a technical review of information and a multilateral assessment of the implementation of emission reduction targets.

${ }^{33}$ See UNFCCC (2012c:38).

${ }^{34}$ European Community (2008).

${ }^{35}$ European Commission (2009).

${ }^{36}$ Carbon Finance at the World Bank: Partnership for Market Readiness. Available on the Internet at http://wbcarbonfinance.org/Router.cfm?Page=PMR\&ItemID=61218\&FID=61218
} 
As for demand for emission units, the EU ETS is currently by far the largest carbon market globally, accounting for about $80 \%$ of all traded value. ${ }^{37}$ For the post-2012 period, the EU has set a unilateral target to reduce its emissions by $20 \%$ by 2020 compared to 1990 levels. If a new international climate change agreement comes into being, the EU is prepared to raise that target to $30 \%$ on the condition that other developed countries commit to similar cuts and developing countries also make adequate contributions. The allowable use of offsets in the EU ETS depends on which target applies.

For the $20 \%$ target, the quantities that were approved for the current period (2008-2012) were basically extended up to 2020. That is, there will be no additional volumes entering the market between 2013 and 2020 over and above what was already allowed for the period 2008 to 2012. If a new international climate agreement is reached which commits the EU to a reduction target greater than $20 \%$, the allowed quantity of Certified Emissions Reduction (CERs) and Emission Reduction Units (ERUs) will be raised by half of the additional reductions required. ${ }^{38} \mathrm{CDC}$ Climat has estimated the maximum amount of credits that could be used in the EU ETS cumulatively over the period 2008-2020 under current conditions at about 1.6 billion. They also estimate that CDM/Joint Implementation (JI) will deliver that amount of credits by 2013-2014, at which point they predict that CER and ERU prices may drop close to zero. ${ }^{39}$

In addition, the so-called "Effort Sharing Decision" implements the unilateral 20\% target for those sectors which are not covered by the EU ETS and divides this target into national shares among the 27 EU Member States. In the absence of a post-2012 international climate change agreement, each Member State may use CDM and JI credits in an amount equivalent to 3\% of their 2005 emissions, with the possibility to bank or trade unused amounts. Twelve Member States may also use an additional $1 \%$ of their 2005 emissions, but only in the form of certificates accrued from projects conducted in least developed countries (LDCs) and small island developing states (SIDS). If there is a new international climate agreement that commits the EU to more than $20 \%$, the allowances for use of CDM/JI credits would also be raised (as with the EU ETS) by an amount equal to half of the additional reduction required. ${ }^{40}$

In addition to the quantitative restrictions, the types of units are also limited. Under current rules, credits from new market mechanisms would not be allowed either under the EU ETS or under the Effort Sharing Decision. However, the EU ETS allows the use of credits "from projects or other emission reducing activities" initiated in accordance with agreements concluded between the EU and third countries. ${ }^{41}$ Also, if the EU ETS and the Effort Sharing Decision were to be amended to adapt the quantitative limits to a higher target, new types of units might also be accepted.

\footnotetext{
${ }^{37}$ Kossoy et al. (2012).

${ }^{38}$ Directive 2009/29/EC of the European Parliament and of the Council of 23 April 2009 amending Directive 2003/87/EC so as to improve and extend the greenhouse gas emission allowance trading scheme of the Community. Official Journal of the European Union, L 140/63 - L 140/86, 5.6.2009. Available on the Internet at http://eur-lex.europa.eu/LexUriServ/LexUriServ.do?uri=OJ:L:2009:140:0063:0087:EN:PDF

${ }^{39}$ Bellassen et al. (2012).

${ }^{40}$ Decision No 406/2009/EC of the European Parliament and of the Council of 23 April 2009 on the effort of Member States to reduce their greenhouse gas emissions to meet the Community's greenhouse gas emission reduction commitments up to 2020. Official Journal of the European Union, L 140/136 - L 140/148, 5.6.2009.

${ }^{41}$ Directive 2009/29/EC, Art. 11a(5).
} 


\section{The United States of America (US)}

The US has pledged to reduce its emissions by $17 \%$ compared to 2005 levels by $2020 .{ }^{42}$ After the failure to establish an ETS at the federal level, the focus has shifted to individual states. On the East Coast, the Regional Greenhouse Gas Initiative (RGGI) has already been operating since 2009. RGGI is a cap-and-trade programme established by a group of North-Eastern and Mid-Atlantic states. ${ }^{43}$ The use of offsets is tied to the carbon price within RGGI. Normally, sources may cover up to $3.3 \%$ of their reported emissions with offsets, but if high prices prevail, the limit may increase in two stages up to $10 \%$. In this final stage, where the $10 \%$ limit applies, entities can also use international units, whereas otherwise they cannot. ${ }^{44}$ Due to the recession and a sharp increase in shale gas production in the US, RGGI prices have been very low, oscillating at about 1-2 USD. A review process that starts in 2012 may however lead to a tightening of the cap.

In addition to RGGI, the Western Climate Initiative (WCI) of several Western US states and most Canadian provinces had set out in 2007 to establish another state-level ETS, but as of 2012, WCI membership has shrunk to include only California, British Columbia, Manitoba, Ontario and Québec. So far only California and Québec have adopted legislation to launch an ETS in 2013. ${ }^{45}$

California has set itself the target to return emissions to 1990 levels by $2020^{46}$ and emissions trading is one major pillar of the effort to achieve this target. The ETS will start with a first compliance period from 2013 to 2014, which will cover large emitters in the energy and industry sectors. In the second compliance period, lasting from 2015 to 2020, the system will be extended to suppliers of oil and gas. The system will thus cover about $80 \%$ of California's emissions. Entities will be able to cover up to $8 \%$ of their compliance obligation through offsets. $^{47}$ The $8 \%$ limit cumulatively translates to about 200 million tonnes by 2020 , but international offsets are currently not eligible. ${ }^{48}$ While California had initially considered allowing the use of CERs, current regulations make no reference to the CDM, mainly due to concerns about the CDM's environmental integrity. ${ }^{49}$ Credits from new market mechanisms under the UNFCCC would also not be allowed under current rules.

\footnotetext{
${ }^{42}$ UNFCCC (2012c).

${ }^{43}$ It covers fossil-fuelled power plants with a nameplate capacity above $25 \mathrm{MW}$.

${ }^{44}$ In detail, if the 12-month rolling average price exceeds 7 USD per short ton, the limit rises to 5\%; and if the 12-month rolling average exceeds 10 USD the limit rises to $10 \%$. In the latter case, participants may also use units from any "governmental mandatory carbon constraining program ... that places a specific tonnage limit on greenhouse gas emissions" - which would include the EU ETS - as well as certified emission reduction credits issued under the UNFCCC or any subsequent protocol, such as the Kyoto Protocol See Section XX-10.3(b)(1) of the Regional Greenhouse Gas Initiative Model Rule, 15 August 2006, revised on 31 December 2008. Available on the Internet at http://rggi.org/docs/Model\%20Rule\%20Revised\%2012.31.08.pdf

${ }^{45}$ Kossoy et al. (2012).

${ }^{46}$ Assembly Bill No. 32, California Global Warming Solutions Act of 2006, An act to add Division 25.5 (commencing with Section 38500) to the Health and Safety Code, relating to air pollution. Available on the Internet at http://www.arb.ca.gov/cc/docs/ab32text.pdf

${ }^{47}$ Final Regulation Order, Subchapter 10 Climate Change, Article 5, Sections 95800 to 96023 , Title 17, California Code of Regulations, to read as follows: Article 5: California Cap on Greenhouse Gas Emissions and Market-Based Compliance Mechanisms. Available on the Internet at http://www.arb.ca.gov/regact/2010/capandtrade10/finalrevfro.pdf

48 No demand for international offsets in California until 2015. Available on the Internet at http://www.pointcarbon.com/news/1.1592240

${ }^{49}$ California Air Resources Board (2011): California's Cap-and-Trade Program, Final Statement of Reasons, October 2011. Available on the Internet at http://www.arb.ca.gov/regact/2010/capandtrade10/fsor.pdf
} 


\section{Australia}

Australia has pledged an unconditional target of reducing emissions by $5 \%$ by 2020 compared to 2000 levels. It is prepared to increase its target to $15 \%$ or $25 \%$ if there is an international agreement and depending on other countries' actions. ${ }^{50}$

In 2011 Australia passed legislation to introduce a carbon pricing scheme from 1 July $2012 .^{51}$ The scheme starts with a period during which the government will be selling allowances at a fixed price of $\mathrm{A} \$ 23 / \mathrm{t} \mathrm{CO}$-eq. emissions, but is to shift to a cap-and-trade ETS by mid-2015. There will be no international trading during this period but Australian Carbon Credit Units (ACCUs) created under the Carbon Farming Initiative (CFI) may be used up to a maximum of $5 \%$ of an emitter's compliance obligation. Once the system shifts to cap-and-trade, entities will be allowed to cover up to half their emissions through imported units as well as unlimited ACCUs. Eligibility is currently limited to Kyoto units with certain limitations. ${ }^{52}$ Credits from new market mechanisms would not be allowed under current rules.

The Australian Treasury had estimated the demand for international units at 92 megatonnes per year by 2020 under the $5 \%$ target. However, analysts consider that actual demand may be much lower as they expect carbon market and economic developments to be much different from what was projected by the Treasury. In addition, the current opposition has pledged to repeal the carbon pricing scheme as soon as it is able to do so. ${ }^{53}$

\section{New Zealand}

New Zealand's post-2012 pledge is a reduction of GHGs of between 10 per cent and 20 per cent below 1990 levels by 2020 , if there is a comprehensive global agreement. ${ }^{54}$

New Zealand has had an ETS (NZ ETS) in place since 2008. It brings in all sectors of the economy over a seven-year period. ${ }^{556}$ The NZ ETS has as a cap the national Kyoto reduction target. A New Zealand Unit (NZU) is the primary domestic unit of trade. It is issued by free allocation to emitters, with no auctions intended in the short term.

The scheme allows the unlimited use of international Kyoto credits, with the exception of forestry CERs (1CERs and tCERs) ${ }^{57}$. Currently, the New Zealand government is undertaking a

\footnotetext{
${ }^{50}$ UNFCCC (2012).

${ }^{51}$ It has downstream coverage of $\mathrm{CO}_{2}$ emissions from fuel use in electricity generation and industry and GHG emissions from industrial processes, mines and waste, as well as upstream coverage of household use of gas.

${ }^{52}$ Regulation currently allows the use of CERs, ERUs and RMUs, subject to the same rules on project types as in the EU, that is exclusion of forestry, hydrofluorocarbons (HFCs), and $\mathrm{N}_{2} \mathrm{O}$ from adipic acid production, but without geographical limitations. Other emissions units, potentially including EU allowances, may be declared eligible in the future. Clean Energy Act 2011, No. 131, 2011 An Act to encourage the use of clean energy, and for other purposes, available on the Internet at http://www.comlaw.gov.au/Details/C2011A00131

${ }^{53}$ Jotzo (2012) notes the following caveats: The history of modelling shows that ex-ante analysis usually underestimates abatement responses; economic growth now looks likely to be lower than projected; Australia has a surplus in the first commitment period; domestic and international price levels will be different from those assumed in the Treasury modelling.

${ }^{54}$ UNFCCC (2012)

${ }^{55}$ See on the Internet at http://www.climatechange.govt.nz/emissions-trading-scheme/

${ }^{56}$ Forestry was the first sector to enter the scheme (on 1 January 2008). Three other sectors joined in July 2010 (liquid fossil fuels, stationary energy and industrial processes). Waste and synthetic greenhouse gas sectors are due to enter the scheme in January 2013 and the agriculture sector in January 2015.

${ }^{57}$ So far New Zealand Units (NZUs) generated locally from forestry have accounted for 64 per cent of units. Other NZUs account for about 31 per cent and CERs only 1.6 per cent. That was because the prices of CERs were higher than NZU prices. See New Zealand Government (2011).
} 
consultation process on an update of the scheme. While a review report recommends the exclusion of CERs with questionable environmental integrity; the New Zealand government consistent with plans in the European and Australian schemes - also intends to introduce a restriction on the proportion of international units an ETS participant can surrender to meet its obligations. ${ }^{58}$ The latter would encourage participants to buy NZUs rather than international units, helping to ensure that there is no excessive overseas purchasing. In general, through the update, New Zealand seeks to align the design features of the NZ ETS more closely with the Australian scheme. ${ }^{59}$

\section{Japan}

The Japanese demand for international credits to meet its pledged target to reduce its GHG emissions by $25 \%$ by 2020 is unclear at the moment. The possibility that Japan will change its target after its 2012 review of its energy and climate policy cannot be ruled out.

Japan has been discussing the introduction of a national mandatory ETS for ten years but no decision to introduce it has been taken so far. Plans made by Japan to implement a comprehensive carbon ETS by 2013 have been put on hold at least until 2014. At the national level Japan has a voluntary trading scheme in place (JVETS), but it has attracted only a very small number of participants. Japan has also had a domestic offset system in place since 2008, creating Japan Verified Emission Reductions (J-VERs). By the end of 2011, 160 projects had been registered. ${ }^{60}$

Mandatory ETSs exist at the regional level in Tokyo, Saitama and Kyoto, with the Tokyo scheme being the third largest cap-and-trade scheme in the world. These regional schemes focus on a reduction of energy consumption by factories and buildings. They have their own regional offset programmes and do not allow international credits to be used. ${ }^{61}$

Another important policy instrument developed to meet the Japanese Kyoto target is a voluntary action plan which has been in place since 1997 - the Keidanren's Voluntary Action Plan. Within Keidanren's Voluntary Action Plan, companies can take targets based on total $\mathrm{CO}_{2}$ emissions, $\mathrm{CO}_{2}$ intensity, energy consumption, or energy intensity. Furthermore, companies can buy and use international credits, ${ }^{62}$ without any limitation, to comply with their targets.

In order to meet the Kyoto target, the Japanese government has a purchase plan of 100 Mio certificates, notably CERs and AAUs. The Japanese government and lately also Japanese companies have been heavily involved in the acquisition of AAUs under green investment schemes in Central and Eastern European countries. Overall, Japan has followed a strategy that seeks to diversify the origin of AAUs. The choice of the seller country has often been motivated by the desire to strengthen economic relations with the host countries and to provide opportunities for exporting Japanese technologies. As AAU trade is regarded as a tool for opening up new markets, sometimes Japanese companies have provided Japanese technology for GHG reduction projects in exchange for small amounts of AAUs. ${ }^{63 .}$

\footnotetext{
${ }^{58}$ New Zealand government (2012).

59 New Zealand government (2012).

${ }^{60}$ Japanese Government (2011).

${ }^{61}$ Tuerk et al. (2012).

${ }^{62}$ CERs, ERUs, and AAUs.

${ }^{63}$ i.e. for electric vehicles.
} 
Technology transfer and enhancing capabilities to utilise the technologies is also a key aspect of the Japanese initiative to develop bilateral offset mechanisms. For its proposed bilateral offset mechanism, Japan has already begun pilot activities. Starting in 2010, Japan has been undertaking feasibility studies of projects involving new mechanisms with the aim of accumulating knowledge and experience, in particular regarding MRV. Based on a tender for projects, the Japanese Ministry of Environment selected 29 new mechanisms projects for the year 2011, mainly in Asian countries but also in South America and Africa. Some of them are related to reducing emissions from deforestation and forest degradation in developing countries (REDD); several focus on those areas and technologies that Japan has already promoted under AAU trading, such as energy efficiency in industry or buildings and transportation. With respect to Ukraine, Japan is considering a continuation and expansion of its activities under AAU trading within a post-2012 bilateral offset mechanism. ${ }^{64}$

\section{Canada}

Canada has pledged a target of reducing emissions by 17 per cent from 2005 levels by 2020 to correspond with the United States' goal. ${ }^{65}$ In Canada, the introduction of a national ETS was discussed for several years, but, with no federal action in the US in sight, these discussions have been put on hold. The Canadian government pulled out of Kyoto in 2011. It never engaged in the purchase of Kyoto credits nor has it presented any concepts for post-2012 market mechanisms.

A regional ETS has been in place in Alberta since 2007 in the form of a baseline and credit scheme. ${ }^{66}$ The ETS in Alberta, however, only accepts domestic (regional) offsets. In November 2009, Québec adopted the target to reduce GHG emissions to 20\% below 1990 levels by 2020. A key instrument for achieving the target will be a cap-and-trade programme passed in December 2011 within the broader context of the WCI, which will start operations in January $2013 .{ }^{67}$ Offset provisions are similar to those of California, with a limit set at $8 \%$ of compliance obligations for each compliance period. Details on the use of offsets have not yet been decided upon. The Quebec scheme will create demand for about 500,000 offset credits over the first compliance period of 2013-2014. California and Québec are currently taking the necessary steps to establish a single regional carbon market with full fungibility of each other's compliance units.

\footnotetext{
${ }^{64}$ Point Carbon, 05 Mar 2012.

${ }^{65}$ UNFCCC (2012c).

${ }^{66}$ World Bank (2012).

${ }^{67}$ From 2013, the cap-and-trade programme will cover about 75 industrial and power facilities emitting more than 25,000 tonnes of CO2 emissions per year. See World Bank (2012).
} 


\section{Countries' positions on the NMM and the Framework ${ }^{68}$}

\subsection{Countries' positions on the NMM}

There are 13 submissions by Parties on the NMM, six submissions by developed countries and seven by developing countries. ${ }^{69}$

\subsubsection{Developed country positions}

The submission by the $\mathbf{E} \mathbf{U}$ is by far the most detailed and essentially contains a rough draft for full modalities and procedures. The EU reiterates its two previously proposed "routes" for the NMM, sectoral crediting and sectoral trading. ${ }^{70}$ The EU suggests that the governance system of the NMM should allow a strong role for the host country, while ensuring that an internationally agreed set of rules are followed to safeguard the environmental integrity of the emissions reductions.

Norway and Japan suggest flexibility in the design of the new mechanism. Norway proposes that there should be a possibility of having different "'windows' or sub-mechanisms". While, in Norway's view, sectoral crediting and/or sectoral trading should be given priority, the mechanism should be flexible enough to include other types of market-based approaches. Norway supports having a centralised governance framework where the UNFCCC is responsible for verification and a single registry issuing and tracking transactions. Japan does not provide much detail. It posits that new mechanisms should include both project-based and sector-based approaches and that these should not be mutually exclusive.

The submissions by New Zealand and the US mostly consist of questions to be addressed in the work programme. The US generally agrees that market-based mechanisms can play an important role in reducing the cost of emission reductions, but does not put forward or endorse any concrete proposal. New Zealand suggests that consideration should be given to how the new mechanism would interact with the framework for various approaches. While there would probably be overlaps, New Zealand would not agree to using the NMM as a substitute for the framework as this would ignore the realities of schemes that already exist or are being planned by countries.

\subsubsection{Developing country positions}

The submission from AOSIS is the second most detailed, after the one by EU, and also proposes sectoral crediting and sectoral trading. AOSIS suggests that the new mechanism

\footnotetext{
${ }^{68}$ For more details see Sterk (2012).

${ }^{69}$ UNFCCC (2012b).

${ }^{70}$ Sectoral crediting would be based on an agreed emissions threshold or "no-lose target" at sectoral level. That is, countries would agree on a target level of emissions for a sector. This threshold could either be set in terms of absolute emissions or be intensity-based, for example in terms of emissions per unit of GDP, emissions per unit of electricity generated, etc. The developing country could then take actions to reduce its emissions to the agreed level, either unilaterally or with some international support. If emissions are reduced below the target, the developing country receives credits. If the target is not achieved, there are no penalties. By contrast, under "sectoral trading", the developing country would receive tradable units ex ante. If the country managed to reduce its emissions below its target, it would thereby achieve a surplus of trading units, which it could sell. If the country did not achieve the sectoral target, it would need to buy trading units to cover the shortfall.
} 
should "bridge the gap" between the project-by-project approach currently available to developing countries through the CDM, and the economy-wide emissions trading available to developed countries under the Kyoto Protocol. The new mechanism should therefore address the sectoral emissions of developing country Parties and deliver substantial net global emission reductions. It should maintain and extend the existing system for the international accounting of emissions and emission reductions developed under the Kyoto Protocol, including its provisions for reporting and review, and eligibility requirements.

Although less detailed, a joint submission by Costa Rica, the Dominican Republic, Mexico, Panama and Peru goes in a similar direction. It proposes that all countries should account for all emissions from all sectors based on principles and criteria set by the UNFCCC. A country could decide to make a share of its emissions available for market instruments. The submission emphasises that this could include one or several sectors, rather than having an instrument that could only operate in one sector.

Ecuador's submission goes into a different direction. It proposes a "net avoided emissions" mechanism for countries whose economies are so far based on extractive industries and which want to transform their economies. This proposal follows Ecuador's Yasuni initiative, by which it would commit to not exploit the fossil fuel reserves below the Yasuni national park if it is compensated for the revenue which it would thus forego. According to the submission, such compensation could be either in the form of direct compensation outside the market, or through market mechanisms.

In contrast to most of the other submissions, China continues to resist the introduction of scaled up mechanisms. Its very short submission posits that the new mechanism should not introduce emission reduction commitments for developing countries and that it "should be project-based and its modalities and procedures should be comparable to those established under the Kyoto Protocol." It also states that the market-based mechanism established under the Convention should not introduce emission reduction commitments for developing countries. The latter point is also emphasised by Saudi Arabia, whose submission otherwise does not go into much detail.

Finally, Bolivia maintains its fundamental opposition to carbon markets, questioning their environmental integrity and compatibility with sustainable development. Bolivia calls for a moratorium on all carbon credits unless there is a "renewed commitment of drastic reductions of GHG emissions in industrialized countries under the Kyoto Protocol".

\subsection{Countries' positions on the Framework}

There are 12 submissions by Parties on the Framework, six submissions by developed countries, including the EU and seven by developing countries. ${ }^{71}$

\subsubsection{Developed country positions}

In contrast to its elaborate submission on the NMM, the EU's submission to the Framework is very short. Without giving details, it stresses that any "tradable emission reduction units" resulting from the Framework would have to "meet the same standards" as those developed under the NMM.

\footnotetext{
${ }^{71}$ UNFCCC (2012a).
} 
Japan's submission is quite elaborate, reflecting the high importance it attributes to this issue. Japan posits that a "one-size-fits-all" approach will not be the best suited for addressing the complex issues that Parties have to address in mitigating climate change. Japan therefore considers it crucial for Parties to establish a wide variety of approaches which best reflect their circumstances while ensuring environmental integrity. It also points to difficulties with the CDM (such as high transaction costs, inequitable geographical distribution, and disproportionate CER issuance from certain types of projects) as a reason for calling for new mechanisms with decentralised governance. It views the Framework as a means to develop its own approaches and favours a decentralised governance system which allows Parties to develop their own standards, ${ }^{72}$ with assistance from the COP in providing basic principles and reporting rules and supporting Parties through the provision of best practices. Standards for implementation, however, would be developed by the Parties themselves.

In line with Japan's submission, New Zealand states that units resulting from the mechanisms established under the Framework may be used by Parties to meet their mitigation commitments. It favours a decentralised governance system attributing no coercive or punitive powers to the UNFCCC. The latter should however assume an important coordination role and should provide guidance, notably on how transparency can be ensured, how minimum common standards could be developed and how the international tracking of units can be guaranteed. In the view of New Zealand, any common standards should be based on IPCC guidelines, should recognise that countries make methodological choices based on their unique circumstances, and allow for flexibility. To address the need for transparency New Zealand proposes the application of a "declaration model" under which Parties provide information on the principal elements of the mechanism, which is then made available by the Secretariat to other Parties for inspection. New Zealand suggests that if the declaration model approach was integrated into the biennial reports and the International Assessment and Review (IAR) and International Consultation and Analysis (ICA) processes for developed and developing countries, this would provide assurance that Parties were using market mechanisms in accordance with the details of their declaration.

According to the United States of America (US), any framework would have to ensure that Parties may develop mechanisms in accordance with their national circumstances that promote real emission reductions, avoid double counting, promote transparency and are consistent with UNFCCC guidelines for MRV. Like Japan and New Zealand, the US views the task of the UNFCC as purely facilitative, possibly playing a role in the tracking of units and the avoidance of double counting, but having no say in determining whether the credits may be used for compliance to meet international mitigation targets. It would be left to governments considering the use of credits toward meeting UNFCCC commitments to determine whether or not the credits are generated according to the principles agreed in the UNFCCC. To ensure transparency, the US stresses that any credits transferred internationally would have to be recorded in a registry. Further, Parties should provide detailed information on the use of standards and methodologies through existing MRV channels in the UNFCCC, including biennial reporting. Similarly to New Zealand, the US suggests that any international transfer of credits could, for instance, be examined as part of the IAR and ICA processes, which would provide Parties the opportunity to request clarification. These processes could finally draw upon an international tracking system to verify that units reported in biennial reports are unique.

\footnotetext{
${ }^{72}$ In particular with respect to overview, eligibility criteria for projects, methodologies, approval and verification of projects as well as the issuance of credits.
} 
Norway's submission does not provide any detail with respect to the governance of the Framework, but underlines the indispensability of a robust common framework for unit accounting, which should apply to all countries that use or offer offset credits. In its view a common framework would help build trust in mitigation commitments, establish a clear relationship between domestic and international compliance units, facilitate the tracking of units and help avoid double counting. It should be established along the lines of the GHG accounting system set up by the Kyoto Protocol and ensure the fungibility with Kyoto units.

According to Switzerland, Parties should establish standards that ensure that the mechanisms developed under the Framework are of comparable quality, foster the fungibility of units and provide security to the private sector regarding their use. Although the UNFCCC would not have to harmonise any single detail according to Switzerland, its submission stresses the importance of defining common standards that include inter alia rules on the avoidance of double-counting, methodologies for crediting thresholds and rules on the tracking of units. Finally, it suggests that a process should be set up that allows the verification of whether the mechanisms meet the internationally agreed standards.

\subsubsection{Developing country positions}

The most comprehensive submission from developing countries stems from AOSIS. Representing probably the opposite extreme to the US position, it states that any units that are used by developed Parties to meet their mitigation commitments under the KP or the Convention will have to be based on a common set of internationally-agreed rules which guarantee at least the same degree of environmental integrity as those that have been set up for the Kyoto mechanisms. Stressing the risks attached to programmes that use different accounting rules and diverging baseline methodologies and entail a significant risk of double counting, AOSIS states that only units that are established at the international level, apply internationally agreed accounting rules and baselines, operate in internationally agreed sectors and are under the direct international oversight should be recognised.

According to Bangladesh et al. ${ }^{73}$ the role of the Framework is to assist developing countries in achieving sustainable development and poverty eradication, while helping developed country Parties achieve compliance with their commitments under the Convention and the Kyoto Protocol. In their view, a regulatory body, operating under the authority of the COP, should oversee the Framework and ensure that a mechanism for the settlement of disputes is established.

China's submission on the Framework is identical to its contribution under the NMM. It is brief and reiterates the position already announced in the run up to Durban that market mechanisms should only be available to developed country Parties that have committed to internationally legally binding emission reduction targets.

Gambia, speaking on behalf of least developed countries (LDCs), does not provide any guidance but stresses the importance of considering the needs of LDCs. Malaysia insists that market mechanisms should not be used as a substitute for real and significant domestic mitigation actions. Finally, Saudi Arabia stresses that the market mechanisms established under the Framework should not negatively affect developing countries.

\footnotetext{
${ }^{73}$ Bangladesh, Cameroon, Central African Republic, Congo, Costa Rica, Côte d'Ivoire, Democratic Republic of the Congo, Dominica, Dominican Republic, Fiji, Gabon, Ghana, Guyana, Honduras, Kenya, Pakistan, Panama, Papua New Guinea, Sierra Leone, Solomon Islands, Suriname and Uganda.
} 
Bolivia also stresses that all mechanisms must operate under the COP and that bilateral or regional agreements should not be eligible for compliance with emission targets under the UNFCCC. In addition, Bolivia highlights that the framework is intended to address not only market-based, but also non-market approaches and proposes the establishment of a "Climate Justice Mechanism". Bolivia considers that industrialised countries' historical emissions constitute an ecological debt that requires a mechanism for compensatory payment.

\subsection{The way forward to Doha ....}

With the crucial exception of China, which favours a project-based approach, there seems to be a broad acceptance that an NMM should be sectoral in nature, be operated under the authority of the COP and designed through a UN process, while allowing for political space at the national level. ${ }^{74}$ Very little consensus, however, has yet been reached with respect to the governance and the roles of the Framework. Developed country Parties favouring a predominantly "bottom-up" approach will probably make approval of the procedures and modalities of the NMM dependent on the recognition of market approaches defined at the national level. On the other hand, developing countries have taken the position that market mechanisms should only be available to developed countries that have adopted internationally legally binding emission targets, which is hardly likely to be acceptable to the US and the countries that have opted out of the second Kyoto commitment period. Given these political differences, it is doubtful that a bold decision will be taken on market mechanisms, be it at the level of the NMM or the Framework, at the next COP. As a result, the current bilateral and regional bottom-up initiatives might well be further developed and implemented without any oversight, but also without recognition by the UNFCCC process.

The current deadlock, however, is no reason to abandon the concept of market mechanisms at the UNFCCC level altogether. As the definition of most developed country Parties' targets is made conditional on the use of offsets and the scale of public finance by developed countries will not meet the needs of developing countries, the issue will most likely remain on the negotiation agenda. Also, as negotiations on the design of new market mechanisms have only just started, there is a clear need to explore further the potential roles of a Framework and the possible designs of its governance. The two following sections will attempt to shed some light on these crucial issues.

\section{Different roles of the Framework}

The submissions of Parties on both the NMM and the Framework broadly reflect the positions defended previously, but are now generally more fleshed out. A large majority of Parties considers that the NMM and the Framework are intimately linked with respect to the goals they pursue. As a result, some Parties have made the same submission under both topics whereas others, like the EU, have stressed that the Framework must meet the same standards as the NMM.

Three potential roles of the Framework can be derived from Parties' submissions: assisting developed countries in achieving their emission targets, ensuring environmental integrity of a future climate regime and achieving net emission reductions and coherence of the international carbon market.

\footnotetext{
${ }^{74}$ See Marcu (2012 a and b).
} 


\subsection{Assisting developed countries in achieving their emission targets}

So far, the post-2012 pledges of developed countries under the Convention are neither legally binding nor have their underlying assumptions been clarified. Most developed country Parties, however, have clearly indicated that they intend to use international carbon units to achieve their targets.

Unlike the provisions regarding the NMM, the text agreed upon in Durban does not mention whether credits generated by mechanisms meeting the conditions of the Framework may be used for compliance with post-2012 targets. Japan, New Zealand and the US, however, have made clear that they want to be able to do so. ${ }^{75}$ Indeed, if this was not the case, the international credits issued by Japan under its bilateral market-based mechanisms or the international offsets accepted under the Californian ETS could not be counted towards the respective national targets. As a result, both Japan and the US would have to compensate the corresponding deficit of emission reductions through other means. In the view of these countries, the Framework is hence clearly meant to be a vehicle by which they and potentially other countries - possibly also developing countries that agree to adopt economy-wide targets - can count units from bilateral schemes towards their post-2012 targets. In other words, the Framework should recognise the validity of international units that have been generated outside the UNFCCC.

\subsection{Ensuring environmental integrity as well as achieving net emission reductions}

Through the use of international credits, countries that are bound by economy-wide emission limitations or reduction targets can comply with their targets by surrendering supplementary units for emissions that exceed their national targets. To ensure that the overall environmental outcome is not undermined, it is necessary to make sure that new mechanisms "deliver real, permanent, additional and verified mitigation outcomes", in other words that "a tonne is a tonne", irrespective of where it comes from.

One important role of the Framework is hence to ensure the environmental integrity of the credits generated by mechanisms meeting its criteria. The views of the Parties, however, differ as to how this goal may be achieved. Whereas Japan, New Zealand and the US consider that transparent reporting and possibly a review under the IAR is sufficient to maintain the environmental integrity of the international carbon market, whereas European and developing countries insist that coherence and integrity can only be guaranteed by common standards. The position of AOSIS is the most pronounced, positing that, "the climate regime already has an internationally-agreed framework for standards and approaches to deliver real, permanent, additional and verified mitigation outcomes for mitigation, established under the Kyoto Protocol". ${ }^{76}$ Any criticisms of the existing flexible mechanisms would in their view be best addressed by making the international rules more uniform, more stringent, and more centralised, rather than less uniform, less stringent and decentralised.

In addition, and in contrast to the CDM, new market mechanisms are supposed to go beyond mere offsetting and achieve a net reduction of GHG emissions. All submissions that address the issue of baselines and crediting thresholds therefore agree that the latter should be set

\footnotetext{
${ }^{75}$ See the submissions on the Framework of these countries in UNFCCC (2012a).

${ }^{76}$ See submission of AOSIS in UNFCCC (2012a).
} 
below business as usual (BaU) levels, so that host countries would have to make a unilateral contribution to GHG emission reductions before credits can be generated.

\subsection{Coherence of the international carbon market}

Currently, several market-based mechanisms are about to be implemented by Parties that may operate outside UN-based rules. In Durban, Parties and observers were concerned that this activity may result in a fragmentation of the carbon market, which would prevent the international recognition of these credits, thereby decreasing the cost efficiency of international climate policy. In particular business organisations maintain that private sector involvement will crucially depend on the fungibility of credits generated through different approaches. $^{77}$

One of the potential roles the Framework may assume is hence to provide the "glue" that connects and recognises future national and regional mechanisms under the UNFCCC. If Parties were to agree on minimal criteria that would guarantee a sufficient level of environmental integrity, carbon credits from different systems could be traded. In this respect robust MRV standards would have an important function, most notably if ETSs are to be linked as well: they should at least be comparable across different systems. Of course such comparability of MRV standards can also be achieved bilaterally, between the schemes that are to be linked. Having internationally agreed standards, however, would make linking easier and would prevent the development of incompatible trading schemes.

Another option would be to create exchange rates, as proposed by the International Emissions Trading Association (IETA). Such a "credit conversion mechanism" (CCM) would be part of the international framework for bottom-up approaches and would provide a means to make various forms of crediting convertible into a single international tradable currency if it was not possible to ensure a comparable design of the mechanism and MRV standards. ${ }^{78,79}$

\section{Design options under the Framework}

While pursuing similar goals, Parties display a wide variety of views on the design options that should be used under the Framework. In their presentation at the UNFCCC workshop on the Framework, New Zealand identified five types of functions for the UN, which could, if need be, also be combined, i.e. a "Library of Parties' Approach", a "Reviewer of mechanism", a "Provider of best Practice Guidance", a "Rule Setter" and a "Centralised Approval Process". ${ }^{80}$ Building on this typology, this section of the paper explores how the various options could be implemented and how they interrelate.

\subsection{The "Library of Parties' Approach"}

The Library of Parties' Approach reflects a model where the involvement of the UN is minimal. Its main objective is to provide transparency on various market approaches

\footnotetext{
${ }^{77}$ See i.e. CMIA (2012).

${ }^{78}$ IETA (2012).

${ }^{79}$ See Sterk (2012).

${ }^{80}$ See presentation made by New Zealand on 18 May at the UNFCCC workshop in Bonn on various market approaches. Available on the Internet at http://unfccc.int/files/bodies/awg-

lca/application/pdf/20120519_nz_1850.pdf
} 
(hereafter "Mechanisms") developed by Parties and to allow other Parties to scrutinise them. No international assessment with respect to the accuracy of the information provided by Parties is required.

The "lightest-touch" version of this model implies that Parties that have established a Mechanism under the Framework are requested to provide basic information, possibly in English, on their procedures, projects and institutional setup as Japan has done for its bilateral offset credit mechanism in its "New Mechanisms Information Platform". 81 A mandate would furthermore have to be conferred upon the Secretariat to establish a website which contains hyperlinks to the Parties' information portals. To ensure that the information provided is relevant, it would be helpful if guidance were provided with respect to the minimal elements that the Parties' Internet Platforms would have to contain.

A more sophisticated model of the Library of Parties' Approach could foresee that in addition to their own websites Parties would have to provide information to the Secretariat according to standardised reporting formats agreed upon at the international level. The Secretariat would then be entrusted with the task of compiling the information and displaying it on its website in a user-friendly form. This would ensure that the information provided by the Parties could be compared easily with the information on mechanisms developed by other Parties.

\subsection{The "Reviewer of Mechanisms"}

Building on the elements developed under the library approach, the Reviewer of Mechanism model adds to the requirement to make information accessible to other Parties the obligation to submit the Mechanisms to an international UN-based review process.

When considering the modalities of a review, decisions would have to be made to determine its scope, objectives, frequency, processes and outputs. As no guidance is provided by the Durban Accord on a review of the mechanisms, with the exception that the mechanisms must lead to verifiable emission reductions, various options may be considered, based on international review processes, in particular the "international assessment and review" (IAR) and "international consultations and analysis" (ICA) agreed upon in Durban.

The scope of a review would depend to a large extent on the form of governance chosen by the Parties. ${ }^{82}$ If it follows a decentralised model a review of only some of the information requirements, or some of the eligibility criteria as defined by the KP for the participation of Parties in the flexible mechanisms, may be conducted. In particular, no review of the environmental integrity of individual projects carried out under the Mechanisms. would be undertaken. The standards for implementation, monitoring and reviewing them would be agreed bilaterally by the implementing parties. ${ }^{83}$

\footnotetext{
${ }^{81}$ See on the Internet at http://www.mmechanisms.org/e/

${ }^{82}$ See for more details de Sépibus et al. (2011).

${ }^{83}$ This may include, according to Japan, an overview of the mechanism (process flow, institutions involved and their roles, etc.); eligibility criteria for the projects and the project selection process, underlying principles of methodologies and their approval process; roles of the third-party certification entities and their accreditation process and approaches to managing projects and credits issued (including measures to avoid double counting). See presentation of Japan at the workshop on 19 May 2012 in Bonn under http://unfccc.int/files/bodies/awglca/application/pdf/20120518_japan_2100.pdf
} 
Under a more centralised governance model, a review could play a far more extensive role. As proposed by the European Union on the NMM, the review could cover guidelines on MRV, the coverage of sectors and gases, baselines and crediting thresholds as well as criteria to determine their contribution to sustainable development. ${ }^{84}$

As is the case under the $\mathrm{IAR}^{85}$ and the $\mathrm{ICA}^{86}$, the main objective of a review would be to increase transparency and to build confidence that the mechanisms established by Parties "deliver real, permanent, additional and verified mitigation outcomes", avoid "double counting" and "achieve net emission reductions".

The question regarding the frequency of review is closely linked to its scope. If the review is limited to the institutional setup of a Mechanism, a single review may be sufficient. However, re-evaluation at regular intervals may be considered in the light of experience gained. If, however, the review is used to determine whether the projects developed under the Mechanisms comply with rules set at the international level, the frequency of the reviews may not be predetermined.

In terms of process, the two-stage review foreseen by the IAR, including, most notably, a technical review and an international assessment, provides an interesting model. During the technical review, a team of experts checks the transparency, accuracy, completeness and consistency with reporting guidelines, as well as the comparability and timeliness of the information provided by the Parties and draws up a technical report. Notably, the Party concerned may interact with the experts and "share any additional information or views". 87 The second stage is a multilateral assessment, which allows a written and oral exchange of views on the technical review and other documents between the Party concerned and other Parties or observers under the aegis of the Subsidiary Body of Implementation (SBI). The SBI forwards conclusions to the relevant bodies under the Convention.

The suitability of the IAR review process depends on the scope of the review of the Mechanism. If the latter covers some basic principles, a two-stage review as foreseen by the IAR represents a viable option. While the accuracy and the consistency of the information provided by Parties may be checked during the technical review, the multilateral assessment gives Parties a good opportunity to gain a more in-depth understanding of the functioning of the Mechanism.

If, by contrast, the scope of the review also covers the compliance of individual projects with international rules, the two-stage IAR model is inappropriate, given the potentially significant number of reviews that it entails. In this case, a "mixed" review process, comprising a twostage review for the assessment of the basic principles and a more "light-touch" technical review of all other rules set at the international level might represent a good compromise. Such an option would allow Parties to participate in an in-depth debate on the essentials of a Mechanism, but leave the review of more technical information to a team of experts.

\footnotetext{
${ }^{84}$ See UNFCCC (2012).

${ }^{85}$ The aim of the IAR is to review the progress made by developed country Parties in achieving emission reductions, to assess the provision of financial, technological, and capacity-building support to developing country Parties, and to assess emissions and removals related to quantified economy-wide emission reduction targets, "with a view to promoting comparability and building confidence".

${ }^{86}$ The main objective of ICA is to increase the transparency of mitigation actions carried out by developing country Parties and their effects.

${ }^{87}$ See 2/CP. 17, Annex II.
} 
Irrespective of the scope and design of the review, it is important to keep in mind that under the "Reviewer of mechanism model" no international institution or body would be empowered to approve or reject a Mechanism or the projects carried out under it. The output of the reviews would be limited to the production of a report, which may contain some recommendations for the Party concerned. As a result, the violation of international rules by the Parties could not be sanctioned, no penalties could be imposed on Parties nor could any rights be withdrawn.

\subsection{A "Provider of best Practice Guidance"}

The term "best practice" refers to a method or technique that shows "results superior to those achieved with other means, and that is used as a benchmark". ${ }^{88}$ It is also used to describe the process of developing a standardised way of doing things. Unlike mandatory rules, best practices are usually not binding for their addressees.

Best or good ${ }^{89}$ practice guidance is a regulatory tool used for many issues within the ambit of the UNFCCC. Best practice guidance ${ }^{90}$ has inter alia been provided for measuring emissions from LULUCF ${ }^{91}$, establishing standardised methodologies for the CDM and to implement Technology Needs Assessments (TNAs). Under the Cancun Agreements, the Technology Executive Committee (TEC) is required to develop "best practice guidelines as facilitative tools for action on mitigation and adaptation" while the Technology Centre and Network (TCN) has "to identify....best practices for country-driven planning to support the dissemination of environmentally sound technologies."

A Provider of best Practice Guidance model may fulfil several purposes under the Framework. For instance, best practice guidance may serve as a source of information and trigger discussions among Parties that wish to set up new Mechanisms. It can further ensure that lessons learned from Parties that are more advanced in this process are shared widely and will assist Parties that want to develop such mechanisms. Finally, it can help Parties to identify problems and gaps with respect to the Mechanisms they have set up, but wish to improve.

Best practice guidance can only be provided if there is past experience that can be built upon. Given the uncertainty as regards the goals that the Framework should pursue, it is difficult to clearly identify the type of information that is relevant for the establishment of best practice guidance with respect to new Mechanisms. If the Framework is to facilitate the linkage of ETSs, the experience with the setup of the European Emission Trading Scheme (EU ETS) provides valuable insights. ${ }^{92}$ If, on the other hand, Annex 1 Parties' intention is to establish Mechanisms that generate credits for compliance purposes, a wealth of lessons may be drawn from the experience gained with the flexible mechanisms under the Kyoto Protocol. Further,

\footnotetext{
${ }^{88}$ See Wikipedia under http://en.wikipedia.org/wiki/Best_practice

${ }^{89}$ At a workshop on policies and measures of Annex I Parties, participants discussed whether the term "good" or "best" should be applied for guidance on practices in an international context. It was agreed that the term "good practice" was more appropriate in an international context because participants considered it unlikely that "best practices" that are effective in one country would necessarily be effective in another country. See UNFCCC (2007: 6 ff.)

${ }^{90}$ In the following the term "best practice" will be used. This does not exclude the possibility that the latter are formulated in a way that takes into account the specificities of each country.

${ }^{91}$ IPCC (2003).

${ }^{92}$ See de Sépibus (2007).
} 
yet still limited findings can be gained from the bilateral "offset schemes" 93 launched by Japan and California. ${ }^{94}$

The development of best guidance presupposes also that Parties are able to agree on a set of evaluation criteria. In this respect the Durban decision on various approaches provides some principles in paragraph 83. Although the conditions set out therein leave considerable leeway for interpretation, they provide a valuable starting point. Given their lack of precision, it is, however, all the more important that the process leading to establishment of best practices is designed carefully.

An interesting model in this respect is provided by the process that has allowed the formulation of good practices for TNAs. ${ }^{95}$ It took place over several years and involved a host of different actors. Initially, a mandate was given to the Expert Group on Technology Transfer (EGTT), whose task was to identify ways to facilitate the transfer of technology. Organised by the Secretariat, a series of workshops were held with representatives of governments and international organisations, as well as experts, to explore various options. Further, a survey on the implementation of TNAs was conducted to provide first-hand experience. Based on these findings a handbook was issued that provided step-by-step guidance on how to transfer technology. The latter was then field-tested and progressively refined over the course of several workshops. This stage of the process allowed Parties to highlight practical aspects relating to the implementation of TNAs, and regional concerns and priorities of developing country Parties. Based on these insights, a synthesis report was prepared and submitted to the EGTT, which issued recommendations for good practices to the Subsidiary Body for Scientific and Technological Advice (SBSTA).

The establishment of good practices for the implementation of TNAs was the product of a long-term collective effort involving the consultation of a multitude of stakeholders. After a preliminary phase of "brainstorming", key information was condensed into a handbook, whose guidance was then tested on the ground and re-evaluated in the light of experience gained. Overall, this example shows that the provision of best practice guidance may be a lengthy process requiring the input of a wide variety of stakeholders.

If best practice guidance were to be provided for the Mechanisms, an international body or institution would have to be entrusted with a clear mandate and endowed with sufficient financial means to carry out the task. Depending on the scope of the guidance, the formulation of well-defined criteria for evaluation at the international level and a review process might constitute necessary prerequisites.

\section{4 "The Rule Setter model”}

Before exploring some design options for the Rule Setter model, a few preliminary clarifications are necessary. From a national law perspective "rules" are usually qualified as legally binding norms that are enforceable. From an international treaty law perspective, the meaning of what constitutes a rule or a legally binding norm is more ambiguous. Based on a conventional international law treaty analysis, rules are only legally binding if they have received state consent and/or are adopted by an institution upon which the explicit authority to

\footnotetext{
${ }^{93}$ The term "offset schemes" refers to mechanisms that allow the use of carbon credits for compliance with mandatory mitigation targets.

${ }^{94}$ See official website on Japan's bilateral offsets and California.

${ }^{95}$ See UNFCCC (2007: 7ff.).
} 
legislate has been conferred by its constituent treaty. ${ }^{96}$ Therefore, norms adopted by Conferences of the Parties in multilateral environmental agreements (MEAs) are rarely legally binding, as in the majority of cases, the legal basis for binding decision-making is lacking. ${ }^{97}$

Through the lens of a conventional analysis, the COP may not play an important rule-making role. ${ }^{98}$ This 'formal perspective', however, does not provide an entirely satisfactory account of the role played by the COP in the field of law-making, in particular within the ambit of the CDM. Hence, when referring to rules in this section, we do not refer exclusively to legally binding norms in a strict sense, but include all types of norms that have been adopted in application of formally agreed procedural rules and which effectively influence the conduct of Parties and/or private actors. ${ }^{99}$

In contrast to best practice guidance, which, if violated, does not entail sanctions, the breach of rules, as they are defined here, is not without consequences. For example, if a Mechanism of a Party does not comply with rules set by the UN, the credits generated under it may not be taken into account in assessing compliance with the mitigation targets of that Party.

The question of the scope of the rule-setting is crucial in two respects. First, it determines the degree of control the international community has over the design of the Mechanisms. If, for instance, "lawmaking" is limited to the setting of criteria for purposes of complying with disclosure requirements, Parties would remain essentially free of any constraints with respect to the design and implementation of their Mechanisms.

Second, it is relevant for shaping the procedural rules governing the rule-setting process. If the "legislative" activities of the COP are meant to remain limited, then rule-setting could proceed directly under the aegis of the COP. If, on the contrary, the scope of the rules was to be extended to criteria regarding the institutional setup of the Mechanism or even further, then the procedures and modalities elaborated for the CDM might provide a commendable model. However, due account would have to be taken of the specificities of the Framework and the limitations that the design of the CDM governance has shown over time. ${ }^{100}$ Indeed, any design would have to carefully balance the need for expediency against the necessity to ensure transparency and accountability.

\subsection{A "Centralised Approval Process"}

The adoption of a rule-setter model as defined here necessarily implies the setup of a centralised approval process. Indeed, only if there is a centralised process during which the compliance of a Mechanism with UN-based rules can be assessed and, in the case of a violation, sanctioned, will the rule-setter model be able to shape state conduct.

Various options have been discussed in the literature ${ }^{101}$ regarding the institutional and procedural requirements of a centralised approval process. Some of the key questions that will have to be addressed concern the composition, the functioning, and the financial endowment

\footnotetext{
${ }^{96}$ Brunnée (2002: 16).

${ }^{97}$ Brunnée (2002: 24).

${ }^{98}$ Brunnée (2002: 6).

${ }^{99}$ Brunnée (2002: 50).

${ }^{100}$ See in particular Streck et al. who point out a lack of application of the rule of law (2008: 411).

${ }^{101}$ See de Sépibus et al. (2011).
} 
of the institution or the body that will carry out this task. ${ }^{102}$ The pros and cons of the various models will not be repeated here. Suffice it to say that the scope of the rule-setting will be crucial for the choice of the final design. If it encompasses a wide range of issues then care has to be taken to ensure that the decision-taking process is sufficiently expeditious while guaranteeing the fair treatment of all Parties.

Other questions concern the procedural rights that might be granted to the participants, in particular the right to appeal a decision. Due account should in particular be paid to the inclusion of due process principles, such as the right to be heard before a decision is made, the right to an impartial decision and the obligation to give reasons when taking a decision. ${ }^{103}$

\subsection{The proposed typology and its combinations}

The typology proposed by New Zealand provides a useful starting point for a further exploration of the implications of various governance design choices. An in-depth analysis shows that some of the models need to be implemented in combination with others. Hence, a review may be implemented only if some information has been disclosed previously by Parties and a rule-setter model may not be applied without a centralised approval process. The various models may further be combined piecemeal, applying a Library model to certain aspects of the Mechanisms while favouring a rule-setter model for others. For example, one option could be to combine a Library model for the implementation of projects with a review for the compliance of the Mechanism with basic principles. Another option could confer a rule-setter role upon the UN, regarding certain minimal institutional requirements, and a mandate to develop best practices for the implementation of projects.

On the spectrum of the roles that the UN may assume in a Framework, the Parties in favour of a "bottom-up" process argue for a light-touch approach, leaving substantial room for manoeuvre to the Parties. Although their views are not yet spelt out in detail, they all oppose a centralised approval model. For instance, Japan favours the setting of general principles and reporting rules at UN level, as well as the provision of best practice, but rejects a system that fixes common standards ${ }^{104}$ with respect to the institutional and operational setup of its mechanisms. In line with Japan, New Zealand favours an approach that builds on best practices, but is ready to consider, under certain circumstances, the setting of minimum common standards. It clearly supports the adoption of a library model to ensure transparency, and proposes including a review under the planned IAR and ICA. The United States (US) favour a library model, implemented through the existing MRV channels of the UNFCCC. Similar to New Zealand it suggests that the international transfer of credits could be examined as part of the IAR and ICA processes and adds that the latter may be complemented by an international system for the tracking of credits.

With the exception of AOSIS, the views expressed by other Parties are in general less precise as regards the governance of the Framework. AOSIS states forcefully that no recognition should be accorded to units that are not generated under international oversight according to internationally agreed rules. AOSIS disputes that there is even a need for a new framework,

\footnotetext{
102 See Bakker et al. (2012).

${ }^{103}$ See Streck et al. (2008: 411).

${ }^{104}$ Standards include, in particular, provisions on the overview of the mechanisms, eligibility criteria, project selection processes, underlying principles of methodologies and processes for their approval, roles of the thirdparty certification entities and processes for their accreditation, as well as approaches regarding the management of projects and the issuance of credits including measures to avoid double counting. See above.
} 
arguing that the Kyoto framework already has all the elements that are needed. At the most recent AWG-LCA session in Bonn China took a similar position, suggesting that the Kyoto rules should be "copy-pasted" and be used as the starting point. While going into less detail, other developing countries also generally maintain the position that units should not be recognised unless they are generated under international oversight. The EU's position is more ambiguous, insofar as it merely points out the necessity that the same standards as those developed under the NMM should apply. So while the EU is in favour of common rules, it does not specify what institutional framework should be established to set these rules and ensure compliance.

\section{Evaluation of the various designs with the Durban mandate}

The Framework should ensure that the standards adopted by Parties deliver real, permanent, additional and verified mitigation outcomes, avoid double counting of efforts, and achieve a net decrease and/or avoidance of GHG emissions. Any governance design will hence have to be measured in the light of these benchmarks.

\subsection{Standards that deliver real, permanent, additional and verified mitigation outcomes and achieve a net decrease and/or avoidance of greenhouse gas emissions}

The requirements that the standards used by Parties must "deliver real, permanent, additional and verified mitigation outcomes" and "achieve a net decrease and/or avoidance of greenhouse gas emissions" boil down to the claim that the "environmental integrity" of the credits must be ensured. The notion at the heart of the latter is the definition of "business as usual" (BaU), or in other words "what would have happened in the absence of the mechanism"? As such, it gives an account of a situation that can only be inferred, not known. ${ }^{105}$ There are different ways defining or operationalising $\mathrm{BaU}$, which may rely on equally valid claims. However, because they rely on projections, they may never be validated or proven wrong with scientific certainty.

It is this inherent relativity of the notion of $\mathrm{BaU}$ which makes the debate on how to ensure the environmental integrity of international offset credits and, correspondingly, what the right level of governance for defining a robust framework would be, so challenging. There is no Party that maintains that a viable result could be achieved through rules set exclusively at the national or the international level. All agree that some form of cooperation between the national and international level should be sought. Clear divides, however, appear as to how the powers should be allocated.

Given that both buyer and seller countries of international credits have strong incentives to generate as many credits as possible, Parties favouring a more centralised approach towards governance stress the need for some form of international oversight that brings the reasonableness of the underlying assumptions under scrutiny and that may require changes if necessary. The Parties favouring a decentralised approach of governance, on the other hand,

\footnotetext{
${ }^{105}$ See Müller (2009)
} 
posit that flexibility and diversity is not contrary to environmental integrity provided that transparency is ensured. ${ }^{106}$

Transparency is at the heart of the Library model. It allows scrutiny and thereby puts pressure on Parties to use reasonable assumptions and standards when establishing a Mechanism. It is also vital to build trust that others are not cheating or abusing the Mechanisms in the pursuit of other goals. To enable the information to be checked by other Parties without too much effort, the latter must, however, also be presented in a comprehensible manner, which allows interested Parties to find the desired information rapidly. In addition, the information must be complete and display all the crucial elements of a Mechanism. Only if these requisites are fulfilled, could the Library Model contribute towards nurturing confidence in the reality of the emission reductions achieved through a Mechanism.

The hopes that information disclosure alone will be sufficient to guarantee the environmental integrity of international carbon credits are probably not well founded. Indeed, in the absence of an international review mechanism it will be up to interested Parties or actors from civil society to verify whether the information supplied is correct and provides sufficient safeguards regarding the environmental integrity of the credits. Such a check however requires both significant resources and in-depth knowledge. It stands to reason that such conditions are not easily to fulfil. It is worth questioning which Parties would be willing and able to devote substantial resources to the task of scrutinising other Parties' bilateral mechanisms, especially as the need for scrutiny would multiply with each new bilateral mechanism. Also, motivations of a political nature may prevent Parties from bringing under scrutiny a Mechanism of another Party. Finally, if the requirement for transparency is not combined with a duty to respond to questions and/or to remedy problems, it will most likely fail to ensure that the standards defined by Parties "deliver real, permanent, additional and verified mitigation outcomes".

An international UN-based review would ensure that the information disclosed is analysed in a systematic way by experts and possibly discussed by political bodies. The effectiveness of any review, however, depends very much on its scope, the resources devoted to it, the competence of the experts carrying it out, their independence, and the possibility of crosschecking information. Also, the absence of a right of the international community to suggest amendments or to sanction possible violations of international principles may substantially reduce the effectiveness of this instrument.

The best practices model provides an interesting tool for standard setting. Given the reluctance of many Parties to adopt coercive international rules, it may provide a good middle way to develop standards step-by-step, based on the sharing of the knowledge of a wide array of stakeholders, involving representatives from both civil society and governments. The effectiveness of this model in ensuring the "environmental integrity" of credits will, however, very much depend on the process through which the standards are developed. Indeed, only a well-designed procedure, which combines both efficiency and openness, can lead to the development of acceptable standards, which would then be widely adopted on a voluntary basis by Parties.

The rule-setter model, combined with a centralised approval process, offers three major advantages. First, it provides an effective counterweight to the inherent incentives of bilateral offset agreements to artificially inflate the number of credits generated. Second, common

\footnotetext{
${ }^{106}$ See the presentation of New Zealand at the workshop on the Framework on 19 May 2012 in Bonn. Available on the Internet at http://unfccc.int/files/bodies/awg-lca/application/pdf/20120519_nz_1850.pdf
} 
rules will have to be adopted according to a uniform procedure accepted by all Parties. Third, all Parties have to abide by a common set of rules, and in the case of violation they may be sanctioned. While these characteristics provide valuable safeguards for maintaining a level playing field and the respect of fundamental principles of procedural fairness, centralised governance by itself does not constitute a guarantee of an environmentally sound outcome. Indeed, notwithstanding the "top-down" architecture of the CDM, the environmental integrity of many of its credits remains disputed. ${ }^{107}$ Hence, the scope of the rules, a robust institutional design, including the ability to carry out reforms to address unforeseen shortcomings, sufficient resources and the possibility to apply effective sanctions for clear violations by Parties will be crucial to ensure the environmental integrity of the Mechanisms.

\subsection{Standards that avoid double-counting of efforts}

If credits resulting from the Framework are used for compliance by developed countries, it is necessary to avoid the emission reductions they represent also being taken into account by developing countries in the fulfilment of their pledges. In such cases the same emissions reductions would be effectively counted twice in the global mitigation effort. The risk that this might occur is real even without the creation of new mechanisms, as reductions from nationally appropriate mitigation actions (NAMAs), which are generally deemed to count towards developing countries' pledges, as well those resulting from CDM projects can easily overlap.

By providing transparency on the origin of the credits generated under the mechanisms, the Library model contributes to addressing the problem of double counting. However, it offers no solution in the case of conflicts. The same is true for the review and the best practices models. As none of these models provides enforceable rules regarding the attribution of credits in case of conflict, the risk of double-counting cannot be addressed with sufficient stringency.

To avoid double-counting, the only reliable solution would probably be provided by a rulesetter model, under which international rules, comprising inter alia common accounting rules for all countries, rules clarifying the "ownership" of international credits, and an international and national registry system comparable to the one that has been set up under the Kyoto Protocol would be made available.

Under Kyoto, all emission units sold by an industrialised country are deducted from its assigned amount. Developing countries, the US, and those countries that will not join the second Kyoto period, will not have AAUs post-2012, so another way of deducting sold units from pledges would need to be found. One potential option would be to add these units to the countries' emission inventories. That is, the inventory would show x tonnes of emissions, and to that total further tonnes would be added for each tonne of emission reductions the country has sold. The pledge would then be compared to the sum of $\mathrm{x}+\mathrm{y}$.

Such an accounting system may also offer an alternative way forward in the case that no agreement on centralised rules for new mechanisms is possible. There is a crucial difference between trading in a capped environment, such as under the Kyoto Protocol or potentially under the new climate agreement that is to be negotiated by 2015, and trading in an uncapped environment. If a country that has a legally binding emissions cap under the Kyoto Protocol issues emission credits that do not correspond to actual emission reductions, it has a deficit

\footnotetext{
${ }^{107}$ See de Sepibus (2011).
} 
with regard to its Kyoto target and will have to compensate for that deficit by achieving or buying emission reductions elsewhere.

Adding sold units to the seller countries' emissions inventory would simulate a cap with respect to emissions accounting. Since all sold units would be deducted from a country's pledge, this would constitute some incentive to only sell units with respect to actual emission reductions. Since the pledges are not binding, however, this incentive would not be as strong as in a system with binding caps. The Environmental Defence Fund (EDF) therefore suggests that only countries that adopt internationally or domestically binding caps for sectoral or national emissions should be eligible to participate in market-based approaches. ${ }^{108}$

\section{Differentiated needs for centralised rules}

A variety of choices need to be made when designing a carbon market mechanism. These relate to participation requirements, coverage, rules for setting baselines, length of crediting/trading periods, and provisions for MRV and emissions accounting. The need for standardisation and centralised rule setting varies considerably between these different elements. This section therefore discusses the need for centralisation separately for each design element. The discussion is again based on the benchmarks set by the Durban mandate. $^{109}$

Participation requirements: Arguably, each country should fulfil a certain set of criteria to become eligible to participate in market mechanisms. In its submission, AOSIS demands strict requirements relating to national emission inventories, but also the US suggests that registries would need to be established by any country wishing to transfer credits or allowances internationally in order to ensure the accurate tracking of units. ${ }^{110}$ The Framework would therefore need to provide at least some centralised rules for participation.

Coverage: The coverage of a market mechanism may range from entire countries, as is the case for international emissions trading under the $\mathrm{KP},{ }^{111}$ to individual projects as in the CDM. ${ }^{112}$ The coverage of GHGs may also differ. In principle, harmonisation of coverage does not seem to be required to ensure environmental integrity. However, boundaries need to be set in a way that would minimise risks of leakage. The framework should therefore have clear rules on how to account for leakage.

Setting baselines: Baselines and crediting thresholds or targets are key components for ensuring the environmental integrity of market mechanisms. They may be determined with respect to $\mathrm{BaU}$ projections, be based on emission benchmarks and policy objectives or set according to technology penetration scenarios. As in an uncapped environment both buyers and sellers have an incentive to inflate the amount of credits generated by a mechanism, baseline methodologies for CDM projects have to be centrally approved. This is not necessary, however, for JI projects, which take place under the Kyoto cap. In the absence of economy-wide emission caps, the Framework should therefore at least provide some core rules for the development of baseline methodologies, in particular regarding the type of data that has to be provided.

\footnotetext{
${ }^{108}$ See Environmental Defense Fund (2012).

${ }^{109}$ See Chapter VI.

${ }^{110}$ Sterk (2012: 16 ff.).

${ }^{111}$ See Art. 17 KP.

${ }^{112}$ See Art. 12 KP.
} 
Length of crediting periods: In theory, there does not seem to be any reason to think that differences in timeframes between various mechanisms are problematic. However, the longer the crediting period, the higher the risk that the baseline will be increasingly unrealistic. There are therefore significant reasons for having a centrally set maximum length of crediting periods to ensure that baselines are updated regularly.

Provisions for measuring, reporting and verification: Next to the setting of baselines, MRV is the other key component for ensuring environmental integrity. Project implementers have an incentive to under-report actual emissions in order to maximise credit generation. The framework should therefore contain minimum standards for the collection and MRV of emissions and other data. Priority areas would be the harmonisation of methodologies for measurement and the determination of data that need to be reported internationally. ${ }^{113}$ The criteria for monitoring developed for JI may present a good example to follow in this respect.

Accounting: As noted in relation to participation requirements, the Framework would need to ensure minimum provisions for the tracking and transfer of units, such as the Kyoto Protocol's system of registries and the international transaction log. In a decentralised system various market mechanisms may exist in parallel. They may be project-based or have a larger scope, e.g. sectoral, in which case there may be overlaps between the mechanisms. For example, there may be CDM projects within the boundaries of a sector-based bilateral mechanism. In addition, without clear accounting rules both buyer and seller may want to count the same emission reductions towards their pledges. The Framework would therefore need to include clear rules to ensure transparent tracking and prevent double counting of emission reductions.

\section{Conclusions}

Currently, emissions trading markets are emerging worldwide, bottom-up, in many regions or countries, such as in California, South Korea and Japan, possibly leading to a fragmented international carbon market. In this context, the Durban Climate Conference agreed on the creation of a new market-based mechanism and to consider the establishment of an overall framework for various mitigation approaches, including opportunities for using markets.

This paper contributes to the discussion on how to design such a framework, in particular with respect to its implications for carbon markets. It presents the different country positions, discusses possible roles and design options and finally evaluates them against the Durban mandate that requires new market mechanisms to deliver real, permanent, additional and verified mitigation outcomes and achieve a net decrease and/or avoidance of greenhouse gas emissions.

The paper shows that there is as yet little consensus with respect to the roles of the Framework. Nevertheless, from the submissions of the Parties, three key roles for the framework may be distinguished: to assist developed countries in achieving their emission targets, to ensure environmental integrity and achieve global net emission reductions, and to guarantee the coherence of the international carbon market.

Strong differences have also been expressed on how to flesh out the Framework so that it may successfully play these roles. On one hand there is a group of developed country Parties,

\footnotetext{
${ }^{113}$ Aasrud et al. (2010: 31).
} 
including Japan, New Zealand and the US, that favours a predominantly "bottom-up" approach with no UNFCCC oversight of the mechanisms developed by countries. In these countries' view the UNFCCC should merely have a facilitative role. On the other hand, the EU and developing countries are in favour of a more centralised framework with common rules. In addition, some developing countries argue that market mechanisms should only be available for developed countries that have adopted internationally legally binding emission targets.

This paper discusses and evaluates several design options for the Framework that range from decentralised to centralised: a "Library of Parties' Approach", a "Reviewer of mechanisms", a "Provider of best Practice Guidance", a "Rule Setter" and a "Centralised Approval Process". The analysis shows that some of the models could be, and others need to be, implemented in combination with others.

Based on the claim for transparency, the Library model allows scrutiny and puts pressure on Parties to use reasonable standards when establishing a mechanism. Its effectiveness in guaranteeing the environmental integrity of credits, however, is limited if it is not combined with a duty of the concerned Party to remedy possible problems. Moreover, in the absence of an international review that ensures that the information disclosed is analysed in a systematic way, it is uncertain whether Parties will be able to play an efficient supervisory role. The Review model addresses some of these problems, as it entails carrying out an international review. Its performance, however, will very much depend on its scope and the resources that are devoted to it. Also, in the absence of a sanctioning power of the international community, it may remain a blunt tool rather than a sharp stick. The Best Practices model may provide a good middle way to develop standards step-by-step, based on the sharing of the knowledge of a large array of stakeholders. Its effectiveness in ensuring a sound environmental outcome will, however, hinge on how the standard setting process is framed and whether best practices are broadly followed by Parties. The Rule-Setter model finally, combined with a Centralised Approval process, may offer major advantages, providing an effective check against the temptation for Parties to inflate artificially the number of credits generated, a uniform standard setting procedure and a common set of rules, and in the case of violation, they may be sanctioned. While these characteristics provide valuable safeguards for maintaining a level playing field, centralised governance by itself does not guarantee the environmental integrity of the credits generated. As the experience with the CDM has shown, a robust institutional design, sufficient resources and the possibility to impose effective sanctions for clear violations by Parties will be vital to ensure a satisfactory outcome.

It is difficult to foresee how the negotiations on the framework will play out. While our analysis suggests that the Rule-Setter model combined with the Centralised Approval process would be best suited for fulfilling the criteria set out in the Durban decision (deliver real, permanent, additional and verified mitigation outcomes, avoid double counting of efforts, and achieve a net decrease and/or avoidance of greenhouse gas emissions) - and this view is probably subscribed to by a large majority of Parties - Japan, New Zealand and the US have so far been strongly against assigning any oversight role to the UNFCCC. These fundamentally diverging views will be hard to bridge.

At the same time, the need for a more centralised framework is arguably enhanced by the lack of legally binding emission targets. If a host country has legally binding emission caps, it is liable if the credits issued do not correspond to actual emission reductions. The country therefore has an interest in making sure that it only issues credits for real emission reductions. In such a system one can easily make a case for leaving the details of a mechanism to the host 
country because the environmental integrity of the overall system would not be affected. However, developing countries do not face such a constraint on their issuance of units. Instead, both sellers and buyers of credits have an interest in generating as many credits as possible. To guarantee the environmental integrity of the carbon market there is hence a crucial need for centralised rules for the setting of baselines and MRV. Also, there is a strong case for harmonisation of methodologies and reporting requirements. Harmonised accounting rules and participation requirements are finally necessary to ensure the tracking of emission units and prevent double counting.

In absence of binding caps a possible solution may be to create a simulated cap with regard to emissions accounting. To prevent a situation where both the host country and the buyer count the same emission reductions towards their pledges, the credits issued would anyway need to be deducted from the host countries' pledge. This would constitute some incentive for the host country only to sell units reflecting real emission reductions. Since the pledges would not be binding, however, this incentive would not be as strong as in a system with binding caps.

Countries that favour a centralised framework hence have essentially two possible options. One option is to dig in their heels, as AOSIS has so far been doing, and flatly refuse to recognise any units as eligible unless they are generated under UNFCCC oversight. Such an approach might transform the so far rather technical issue of the framework into a high-level political issue. The other option would be to take the rhetorical commitment by Japan, New Zealand and the US to high standards at face value and dedicate substantial resources to reviewing these countries' bilateral mechanisms in the framework of the IAR and ICA processes.

In practice, however, in the absence of UNFCCC oversight, the task of scrutinising other countries' bilateral mechanisms would probably fall mostly on the EU as most developing countries would probably have no capacity to spare for this purpose. Most UNFCCC Parties would therefore have to blindly believe the claims that bilateral mechanisms adhere to high standards.

Creating a strong central capacity at UNFCCC level according to the rule-setter and reviewer models is therefore the only option that is able to comfortably assure the vast majority of UNFCCC Parties that environmental integrity is in fact ensured. One may nevertheless question whether each detail would need to be regulated at UNFCCC level or whether some reasonable balance could be struck between centralisation and flexibility. Further work could therefore focus on examining the individual design elements of market mechanisms (rules for coverage, boundaries, baseline setting, MRV etc.) in more detail to determine what level of centralisation is necessary for each of them. 


\section{Bibliography}

Aasrud André, Baron Richard, Buchner Barbara, McKall Kevin (2009). Sectoral Market Mechanisms - Issues for Negotiation and Domestic Implementation, International Energy Agency (IEA)/Organisation for Economic Co-operation and Development (OECD), Paris. Available on the internet at https://www.iea.org/papers/2009/sectoral_market_mechanisms.pdf

Bakker Stefan and Seijm Jos (2012). Design elements for new market mechanisms, EU Side event SB 36, Bonn, 16 May 2012. Available on the internet at http://regserver.unfccc.int/seors/attachments/get_attachment?code=06ZVP3N6CKC2BSD981 88RZMWKCJ1U6TT

CMIA (Climate Markets \& Investment Association) (2012). CMIA submission in response to para 81 of COP17 LCA Outcome. Available on the internet at http://unfccc.int/resource/docs/2012/smsn/ngo/162.pdf

Bellassen Valentin, Stephan Nicolas, Leguet Benoit (2012). Will there still be a market price for CERs and ERUs in two years time? Climate Brief $n^{\circ} 13$. Available on the internet at http://www.cdcclimat.com/IMG//pdf/12-05_climate_brief_no13_-

_supply_demand_for_cer_eru_in_the_ets.pdf

Brunnée Jutta (2002). COPing with Consent: Law-Making Under Multilateral Environmental Agreements, Leiden Journal of International Law, v. 15, pp. 1-52.

Butzengeiger-Geyer Sonja, Castro Paula, Dransfeld Björn, Michaelowa Axel, Okubo Yuri, Skogen Anders, Tangen Kristian (2010). New Market Mechanisms in a Post 2012 Climate Regime - Challenges and Opportunities, Report to the German Federal Environment Agency (unpublished).

Butzengeiger Sonja, Dransfeld Björn, Cames Martin, Michaelowa Axel, Healy Sean (2012). New Market Mechanisms for Mitigation - Getting the Incentives Right, in: Michaelowa Axel (ed.), Carbon Markets or Climate Finance? Low Carbon and Adaptation Investment Choices for the Developing World, pp. 146-167.

De Sépibus Joëlle (2011). The Clean Development Mechanism - A critique of its environmental integrity, in: Michael Mehling/Amy Merril/Karl Upston-Hooper, Improving the Clean Development Mechanism: Legal and Institutional Challenges, Berlin, Lexxion, 2011.

De Sépibus Joëlle, Tuerk Andreas (2011). New market-based mechanisms post-2012: institutional options and governance challenges when establishing a sectoral crediting mechanism, Environmental Liability, v. 19, n. 4, pp. 111-130.

European Community (2008). France on behalf of the European Community and its Member States', Further Input in relation to possible improvements to emissions trading and the project-based mechanisms under the Kyoto Protocol, Submissions by Parties, FCCC/KP/AWG/2008/MISC.7, 13 November 2008, 3-13. Available on the internet at http://unfccc.int/resource/docs/2008/awg6/eng/misc07.pdf 
European Commission (2009). Communication from the Commission to the European Parliament, the Council, the European Economic and Social Committee and the Committee of the Regions, Towards a comprehensive climate change agreement in Copenhagen, Brussels, $\operatorname{COM}(2009) \quad 39$ final. Available on the internet at http://eurlex.europa.eu/LexUriServ/LexUriServ.do?uri=COM:2009:0039:FIN:EN:PDF

Environmental Defense Fund (EDF) (2012). Submission of The Environmental Defense Fund (www.edf.org) on paras. 79-86 of the Durban Decision on various approaches, including opportunities to use markets. Available on the internet at http://unfccc.int/resource/docs/2012/smsn/ngo/204.pdf

Harrison David, Lo Passo Francesco, Radov Daniel, Nichols Albert, Klevnas Per, Foss Andrew (2011). Evaluation of Incentives in International Sectoral Crediting Mechanisms, A Report for Enel, NERA Economic Consulting, Boston, Rome. Available on the internet at http://www.nera.com/nera-files/PUB_Enel_Report_102411.pdf

Helme Ned, Whitesell William, Houdashelt Mark, Osornia Juan, Ma Haibing, Lowe Ashley, Polzin Thomas (2010). Global Sectoral Study: Final report, Center for Clean Air Policy, Washington, DC. Available on the internet at http://www.ccap.org/docs/resources/934/CCAP\%20Final\%20Sectora1\%20Report.pdf

IETA (International Emissions Trading Association) (2012): IETA response to the AWGLCA call for input regarding new market- based mechanisms. Available on the internet at http://unfccc.int/resource/docs/2012/smsn/ngo/168.pdf

International Energy Agency (IEA)/Organisation for Economic Co-operation and Development (OECD) (2010): Scaled-up market mechanisms - What is needed to move forward? A summary of recent OECD/IEA analyses, International Energy Agency (IEA)/Organisation for Economic Co-operation and Development (OECD), Paris. Available on the internet at http://www.oecd.org/dataoecd/54/4/44200317.pdf

IPCC (2003). Good Practice Guidance for Land Use, Land-Use Change and Forestry, available on the internet at http://www.ipcc-nggip.iges.or.jp/public/gpglulucf/gpglulucf.html

Japanese Government (2011). New Market Mechanisms Express. November 2011.

Jotzo Frank (2012). Australia as a buyer in international emissions markets? JIKO Info 2/2012 (forthcoming).

Kossoy Alexandre, Guigon Pierre (2012). State and Trends of Carbon Market 2012, World Bank, Washington, DC. Available on the internet at http://siteresources.worldbank.org/INTCARBONFINANCE/Resources/State_and_Trends_20 12_Web_Optimized_19035_Cvr\&Txt_LR.pdf

Marcu Andrei (2011a). Post Durban: Moving to a fragmented carbon market world? Climate Change, CEPS Commentaries. Available on the internet at http://www.ceps.eu/book/postdurban-moving-fragmented-carbon-market-world

Marcu Andrei (2011b). The Durban Outcome, A post 2012 Framework Approach for Green House Gas Markets, in: The UNEP Risø Centre Energy and Carbon Finance Group, Progressing towards post 2012 carbon markets, pp. 127-137. 
Marcu Andrei (2012a). Meeting Notes- CEPS Carbon Market Forum, Task Force: New Market Mechanisms under UNFCCC, 2nd meeting of the Task Force, March 22nd, 2012. Available on on the internet at http://www.ceps.eu/files/task_force/2012/02/TFNMMSummarySecondMeeting22032012.pdf

Marcu Andrei (2012b). Expanding Carbon Markets through New Market-based Mechanisms: A synthesis of discussions and submissions to the UNFCCC, Climate Change, CEPS Special Reports, see on the internet under http://www.ceps.eu/book/expanding-carbon-marketsthrough-new-market-based-mechanisms-synthesis-discussions-and-submissi

New Zealand government (2012). Updating the New Zealand Emissions Trading Scheme: A consultation document. Available at http://www.climatechange.govt.nz/consultation/ets/

Point Carbon (2012). Ukraine, Japan mull bilateral scheme. 05 Mar 2012

Schmidt Jake, Helme Ned, Lee Jin, Houdashelt Mark (2008). Sector-based approach to the post-2012 climate change policy architecture, Climate Policy, v. 8, pp. 494-515.

Schneider Lambert, Cames Martin (2009). A framework for a sectoral crediting mechanism in a post-2012 climate regime, Report for the Global Wind Energy Council, Öko-Institut., Berlin. Available on the internet at http://www.oeko.de/oekodoc/904/2009-022-en.pdf

Sterk Wolfgang (2010). New Mechanisms for the Carbon Market? Sectoral Crediting, Sectoral Trading, and Crediting Nationally Appropriate Mitigation Actions, Wuppertal Institute for Climate, Environment, Energy, Wuppertal. Available on the internet at http://www.jiko-bmu.de/english/background_information/publications/doc/961.php

Sterk Wolfgang (2012). Current Proposals and Positions on New Market Mechanisms, Wuppertal Institute for Climate, Environment and Energy, Wuppertal. Available on the internet at bmu.de/english/background_information/publications/doc/1152.php

http://www.jiko-

Sterk Wolfgang, Arens Christof, Mersmann Florian, Wang-Helmreich Hanna, Wehnert Timon (2011). On the Road Again. Progressive Countries Score a Realpolitik Victory in Durban While the Real Climate Continues to Heat Up, Wuppertal Institute for Climate, Environment, Energy, Wuppertal. Available on the internet at http://www.wupperinst.org/en/info/entwd/index.html?beitrag_id=1864\&bid=42\&searchart=

Streck Charlotte, Lin Jolene (2008). Making Markets Work: A Review of CDM Performance and the Need for Reform, The European Journal of International Law Vol. 19 no. 2, pp. 409442

Tuerk Andreas, Mehling Michael, Klinsky Sonja (2012). Emerging domestic Carbon Markets: lessons and key challenges. Climate Strategies Working Paper, (forthcoming).

UNDP Environment and Energy Group (2012). Taking Stock of Durban, Review of Key Outcomes and the Road Ahead, on the internet under http://www.undpcc.org/docs/Bali\%20Road\%20Map/English/UNDP_Taking\%20Stock\%20of $\% 20$ Durban.pdf 
UNFCC (2007). Good practice for technology needs assessments, background paper,

UNFCCC workshop on sharing good practices with conducting technology needs assessments Bangkok, available at the internet at

http://unfccc.int/ttclear/pdf/Workshops/Bangkok/Paper.pdf.

UNFCCC (2012a). Ad Hoc Working Group on Long-term Cooperative Action under the Convention, Views on a framework for various approaches, Submissions from Parties, available on the internet at http://unfccc.int/resource/docs/2012/awglca15/eng/misc04.pdf

UNFCC (2012b). Ad Hoc Working Group on Long-term Cooperative Action under the Convention, Views on the market-based mechanism, Submissions from Parties http://unfccc.int/resource/docs/2012/awglca15/eng/misc06.pdf

UNFCCC (2012c). Quantified economy-wide emission reduction targets by developed country Parties to the Convention: assumptions, conditions, commonalities and differences in approaches and comparison of the level of emission reduction efforts. Technical paper. FCCC/TP/2012/2, 8 May 2012.

Worldbank (2012). State and trends of the Carbon market. Available on the internet at http://siteresources.worldbank.org/INTCARBONFINANCE/Resources/State_and_Trends_20 12_Web_Optimized_19035_Cvr\&Txt_LR.pdf 